Mini review

\title{
The unbearable lightness of bone marrow homeostasis
}

\author{
Dimitrios Agas $^{\mathrm{a}, *}$, Luigi Marchetti ${ }^{\mathrm{a}}$, Eleni Douni ${ }^{\mathrm{b}, \mathrm{c}}$, Maria Giovanna Sabbieti $^{\mathrm{a}}$ \\ a School of Biosciences and Veterinary Medicine, University of Camerino, Via Gentile III da Varano, Camerino (MC), Italy \\ ${ }^{\mathrm{b}}$ Laboratory of Genetics, Department of Biotechnology, Agricultural University of Athens, Athens 11855, Greece \\ 'Biomedical Sciences Research Center "Alexander Fleming", Vari 16672, Greece
}

\section{A R T I C L E I N F O}

\section{Article history:}

Available online $\mathrm{xxx}$

\section{Keywords:}

Bone marrow

Bone remodelling

Bone physiology

Mesenchymal stem cells

Hematopoietic stem cells

\begin{abstract}
A B S T R A C T
The anatomical and functional dimensions of bone marrow topography have been at the forefront of modern bone and immunological research for many years and remain a source of complexity and perplexity due to the multitude of microhabitats within this microenvironment. In fact, research has uncovered fascinating functional aspects of bone marrow residents, and the bone marrow niche has been identified as the foremost reservoir of a variety of cells including hematopoietic, skeletal and endothelial stem/progenitor cells. The physical interactions of the marrow residents, combined with the release of cytokines and growth factors, organize well-defined operative compartments, which preserve bone and immune cell homeostasis. In a simplistic view, both the hematopoietic and bone marrow stromal (mesenchymal) stem/progenitor cell populations dwell at the interface between the endosteum and the bone marrow area (endosteal niche) and in the perivascular space (vascular niche). Indeed, the tantalizing hypothesis of bone marrow regulatory dependency on these niches is supported by current research insofar as the increase in the number of osteoblasts results in a concomitant increase in the hematopoietic population, indicating that the osteoblasts and the endosteal niche are key components of HSC maintenance. On the other hand, impaired function of the vascular niche compromises the endosteal niche's ability to support hematopoiesis. These fascinating discoveries indicate that there are strong ties between bone marrow inhabitants within the confines of the bone marrow itself. When these ties fail, niche-niche communication suffers and results in reduced bone formation, enfeebled hematopoiesis and unrestrained HSC migration through blood circulation. This study focused on the extraordinary homeostatic equilibrium and function of both bone and immune cells within the spatially defined microenvironment of bone marrow. But how important is the anatomically outlined scenery in which the bone marrow entity supports and hosts the hematopoietic elements?
\end{abstract}

(c) 2014 Elsevier Ltd. All rights reserved.

\section{Introduction}

The vertebrae, hips, ribs, skull and long bone cavities host a remarkable multicellular network in terms of complexity, integrity, functionality and dependency: bone marrow. The bone marrow microenvironment is committed to accommodating the hematopoietic and the bone stem/progenitor cells in a symbiotic, multifaceted setting. The hematopoietic stem cell (HSCs) population is a heterogeneous cell assortment including long-term (LT) and short-term (ST) components [1]. Under normal conditions the majority of the HSCs within the bone marrow are dormant or

\footnotetext{
* Corresponding author at: Dimitrios Agas School of Biosciences and Veterinary Medicine, University of Camerino, Via Gentile III da Varano, Camerino, MC, Italy. Tel.: +390737 402715; fax: +390737402708.

E-mail address: dimitrios.agas@unicam.it (D. Agas).
}

slowly cycling. According to Cheshier et al. [2] 75\% of LT selfrenewing HSCs remain in the G0 state. This state maintains HSC homeostasis through the control of self-renewal, proliferation and differentiation of the HSCs and progenitors [3]. The HSCs give rise to lymphoid progenitors, which differentiate to become immune cells and myeloid progenitors, which mature into osteoclasts, macrophages, neutrophils, basophils, eosinophils, megakaryocytes, erythrocytes and dendritic cells [4].

The bone marrow stromal microenvironment encompasses multiple cell types including bone-lining osteoblasts, endothelial cells, reticular adventitial cells, neuronal and muscle stem cells and mesenchymal stem and progenitors components. The bone marrow-derived mesenchymal stem cells (MSCs) consist of a self-renewing marrow population with multilineage potential, physically present in concomitance with the HSCs. The MSCs have recently been portrayed as perivascular cells with well-defined roles in microvessel wall formations and in the HSC architectural 
niche framework [reviewed in 5]. The MSCs possess a plasticity grade and, although they are not a pluripotent cell population (their stemness properties are still an open debate, which tip the balance in favor of a peculiar non stem/progenitor cell behavior), can provide bone marrow functional cells, including osteoblasts, chondroblasts, fibroblasts, adipocytes and endothelial cells [4,6]. The far-reaching MSC features are responsible for the assembly and organization of the hematopoietic, skeletal and perivascular niches within the marrow cavity, and, thus, MSCs have been designated as the preeminent niche manufacturers. Schofield's pioneer study [7] gave prominence to the niche concept and spurred interest in stem cell research and its spatial dimension, giving rise to fascinating, as well as, in some cases, contradictory standpoints. The most important result of this prior research is the structural and functional singularity of the bone marrow niches and the value of each niche. From this point of view, both MSC and HSC niches share distinct anatomical districts with significant functional differences and complexities. This scenario involves the mature lymphoid components, the endosteal cells (including osteocytes, osteoblasts, osteoclasts and macrophages) and the sinusoids, which are demarcated by endothelial cells and adventitial reticular cells (Fig. 1). In an elegant study, Sacchetti et al. [8] use the CD146 marker, a cell adhesion molecule of the immunoglobulin superfamily, to distinguish MSCs from the other osteogenic and non-osteogenic progenitors. The $\mathrm{CD}_{146^{+}}$stromal cells, on the one hand, generate osteoblasts, which prepare the endosteal niche, and, on the other hand, differentiate into sinusoidal adventitial reticular cells, giving rise to the sinusoidal wall structure and organization. Both the endosteal and sinusoidal regions define strategic bone marrow areas, which contribute to HSC homing and maintenance [8,9]. The niche milieu presents two types of interaction: 1) an adhesive interaction between stem/ mature cells within the niches [10]; 2) indirect interactions through cytokines/chemokines and other molecular mediators [reviewed in 11,12]. The interchanges between these mediators/ cell-cell interactions guarantee stem cell activities within the niches and maintain bone marrow homeostasis. Accordingly, the bone-lining osteoblasts synthesize a vast number of cytokines, which can expand the number of LT-HSCs approximately 2-4-fold and support the hematopoietic stem/progenitor lineage [13,14]. Moreover, an increase in the osteoblast population reflects an increase in LT-HSCs [14] and, correspondingly, osteoblasts cotransplanted with HSCs considerably improve engraftment. As indicated by El-Badry et al. [15], the bone progenitor cells or the osteoblasts may be crucial components of the stromal cell population and facilitate engraftment of marrow stem cells in an allogeneic environment. Intriguing studies prove that not only can HSCs differentiate into MSCs but myeloid cells can also develop

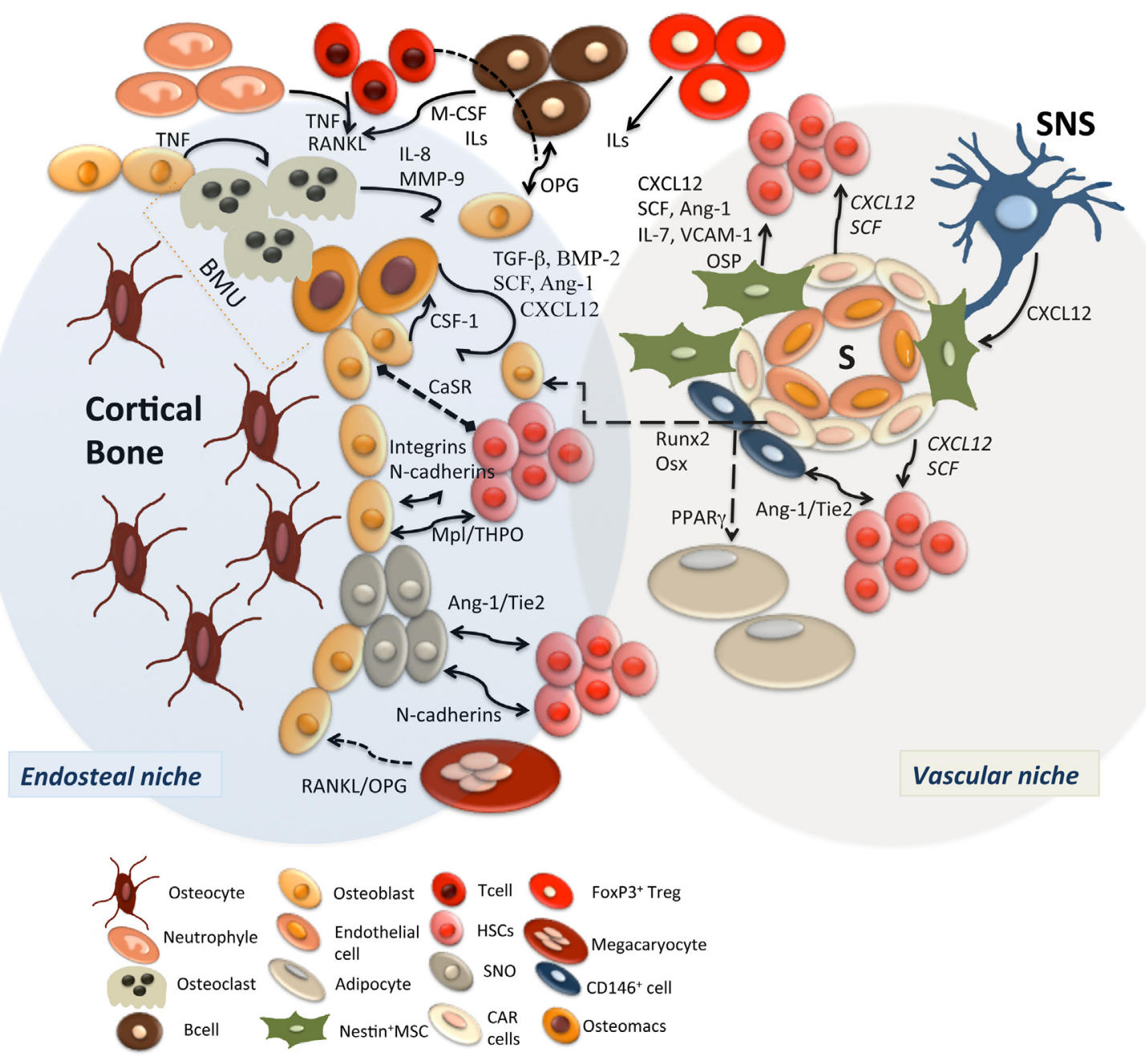

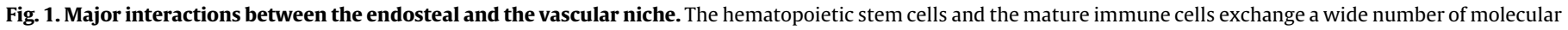

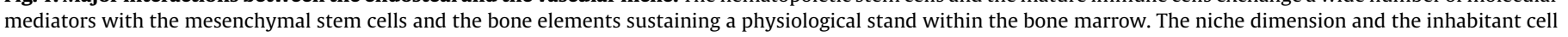

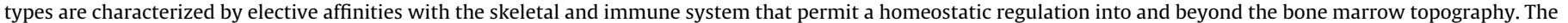

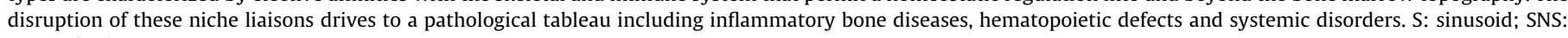
sympathetic nervous system. 
a mesenchymal capability [reviewed in 16], which fundamentally alters the landscape of how we understand the bone marrow cavity. From this point onward, the conception of how the niche microenvironment manipulates the bone marrow dimension has been at the forefront of innovative research on MSC related therapies, HSC engraftment techniques and autoimmune disease treatments.

\section{Does bone marrow ontogeny encompass more than one functional niche?}

Over the last decade research has identified a number of interactions within the bone marrow and their protagonists, fueling the investigation of the spatial relations between these homeostatic components. The anatomically defined areas that bring into play the MSC and the HSC metabolites have not always been considered anatomically and functionally interdependent. Although the endosteum can even be at a 5-cell distance from the sinusoids [17], these two anatomical compartments have been considered either as distinct niches with exclusive functions or subcompartments of a single niche. In this view, Méndez-Ferrer et al. [18] have denoted that within bone marrow there is a unique niche shaped of heterotypic stem-cell pairs, although several sets of evidence support the existence of a multi-niche tableau. In addition, HSCs reside at the endosteal surfaces, which provide signals for their homing and regeneration (endosteal niche). Thus, a body of evidence suggests that the trabecular bone area is the primary site for HSC homing [14]. A paradigm of the multi-niche concept originates from the fact that the HSCs were also found close to the walls of sinusoids, the blood vessels of the bone marrow cavity (vascular niches) [19-21] (Fig. 2A, B). Kiel et al. $[17,22]$ propose that a minority of HSCs localize near the endosteal surface $(<20 \%)$ and a majority of HSCs $(>60 \%)$ are confined to the sinusoid. The same authors have also suggested that HSCs cannot localize to the endosteum without being perivascular, and potentially influenced by factors secreted by endosteal cells [23]. Likewise, it has been shown that the endosteal niche maintains HSC quiescence [14,24,25] whereas the vascular niche supports stem/progenitor cell homeostasis and regulates megakaryopoiesis [26]. The physiological significance of these findings delineate a complex microarchitecture in bone marrow. The distinct anatomical compartments include the candidate niches, which act as coordinators of the bone marrow microenvironment.

\subsection{Spindle-shaped $\mathrm{N}$-cadherin ${ }^{+} \mathrm{CD} 45^{-}$osteoblastic cells}

In point of fact, specialized cell-residents have been identified with a niche-related function. A population of osteoblasts adjacent to the bone surface, called spindle-shaped $\mathrm{N}$-cadherin ${ }^{+} \mathrm{CD} 45^{-}$ osteoblastic (SNO) cells, coalesce with the bone-lining osteoblasts to provide the HSCs a niche within the bone marrow. Zhang et al. [14] show that the SNO cells enrich both the trabecular bone surface and the endosteal surface of the long bones. SNO cells support HSCs (in particular by maintaining the LT-HSCs quiescent/ slow cycling status) by virtue of $\mathrm{N}$-cadherin and $\beta$-catenin cell-cell interactions. It has also been suggested that the increased number of SNO cells points to an increased number of HSCs, and therefore SNO cells have been identified as key components of the niche [14]. However, contradictory studies affirm that $\mathrm{N}$-cadherin interactions do not have a fundamental role in HSC maintenance; HSCs express low levels of $\mathrm{N}$-cadherin and the lack of $\mathrm{N}$-cadherin in knockout mice does not influence the ability of HSCs to sustain either hematopoiesis over time or bone marrow cellularity $[23,27]$. Considering the data reviewed above it remains questionable whether HSC retention, at the endosteum level, by an N-cadherin-independent mechanism depends on direct contact with osteoblasts or on indirect interactions between various bone marrow cell populations. To address this issue, Arai and Suda [28] pointed to the fact that, since HSCs adjacent to the osteoblastic niche have greater $\mathrm{N}$-cadherin levels compared to those situated in the vascular niche [14], the various $\mathrm{N}$-cadherin expression levels exert a watchdog role on HSC localization among the niches.

\subsection{Thrombopoietin/Mpl interactions}

Quiescence of LT-HSCs is a crucial condition that preserves and protects the stem cell pool whenever it occurs [29]. LT-HSCs express the thrombopoietin (THPO) receptor, called Mpl, and the bone lining cells at the endosteum level produce THPO. THPO was initially acknowledged as a key regulator of megakaryocyte and platelet metabolism [30]. Further earlier studies, using Thpo-/and $\mathrm{Mpl}-/-$ mice, showed impaired HSC maintenance and cell cycle kinetics [31-33]. Later, the THPO/Mpl signalling interaction was proposed as an important pathway for the maintenance of LTHSCs within bone marrow [25,34]. THPO/Mpl interaction modulates HSC cycle progression and preserves LT-HSCs quiescence through regulation of cell-cycle mediators such as $\mathrm{p} 57^{\mathrm{kip} 2}$, p19 ${ }^{\text {Ink4d }}$, Myc and various Homebox transcription factors involved in HSC self-renewal $[25,33]$. Moreover, THPO induces the expression of cell adhesion molecules, such as $\beta 1$-integrin, supporting the thesis of direct niche-niche interactions [25]. Although impaired Myc function induces overexpression of integrins and $\mathrm{N}$-cadherins in HSCs, resulting in a reduced ability to proliferate and uncontrollable cell adhesion, a THPO/Mpl-induced Myc decrease induces the regulation of cell adhesion molecules and HSC anchoring [35]. Keeping in mind that $\beta 1$-integrin plays a critical role in the colonization of hematopoietic organs by HSCs during embryogenesis and postnatal bone marrow hematopoiesis [36], the functional dimension of the THPO/Mpl signalling becomes explicable. Insofar as $\mathrm{Mpl}^{+} \mathrm{HSCs}$ are localized in the endosteal area adjacent to the THPO-producing osteoblasts, these observations clearly indicate the involvement of the endosteum cells in HSC metabolism.

\subsection{Tunica endothelial cell kinase 2 receptor/angiopoietin-1 signalling}

Supporting the concept that the endosteal niche orchestrates bone marrow homeostasis, Arai et al. [24] have demonstrated the importance of tunica endothelial cell kinase 2 receptor (Tie2)/ angiopoietin-1 (Ang-1) signalling in HSC homeostasis and its critical role in the self-renewal ability of HSCs. Ang- 1 is well known as the key component of angiogenesis and contributes to the remodelling of the slow flow sinusoids within the bone marrow [37]. It is also accepted that Tie2 is expressed on endothelial cells as well as on HSCs [38,39] and its ligand Ang- 1 is produced by CD $146^{+}$ osteoprogenitors [8] and by osteoblasts [40]. Tie2 ${ }^{+}$HSCs are quiescent, exert anti-apoptotic activities and are localized adherent to the bone-lining osteoblasts. The Tie2/Ang-1 binding supports tight adhesion of HSCs to the niche through a $\mathrm{N}$-cadherin/ $/ \mathrm{B} 1$ integrin-dependent mechanism, which results in HSC maintenance and survival [24]. As previously reported regarding THPO/Mpl signalling, Tie2/Ang-1 interaction facilitates HSC adhesion to the niche and provides additional support for the importance of HSCbone cell communication at the endosteal level. Another study [8] shows that the endosteal and perivascular niches are functionally interdependent. Specifically, via Ang- 1 production, $\mathrm{CD}_{146^{+}}$subendothelial cells and $\mathrm{CD} 146^{+}$stromal cells regulate the vascular remodelling and the organization of the vascular structure, which provide molecular and mechanical support for HSC homing [8]. 

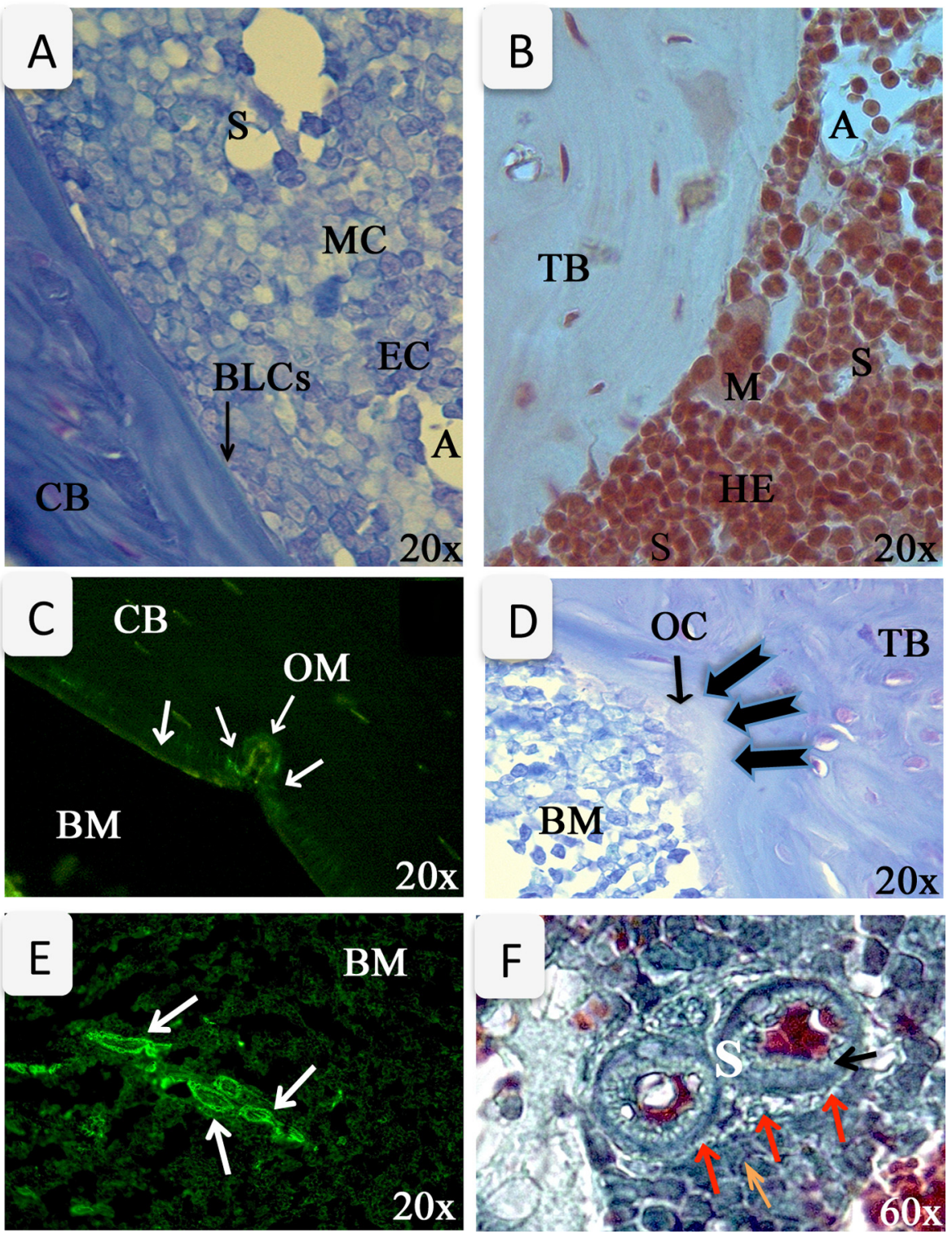

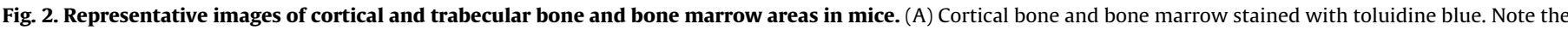

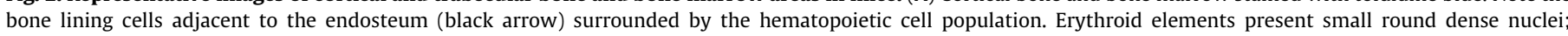

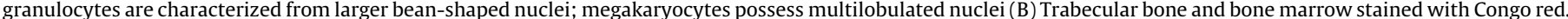

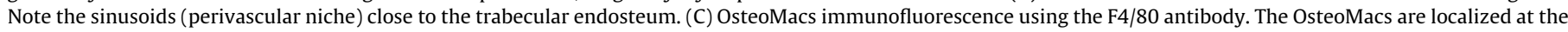

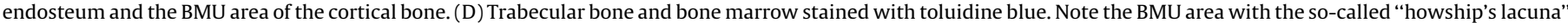

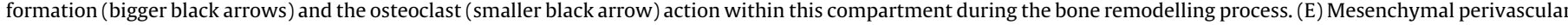

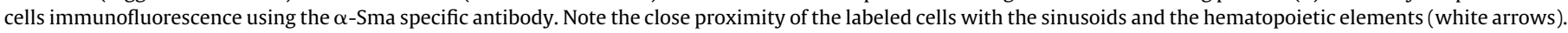

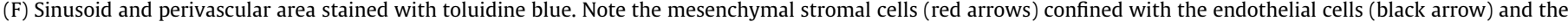
hematopoietic population (orange arrow) organizing the vascular niche.

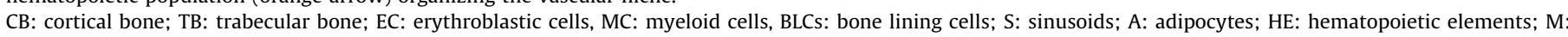
megakaryocyte; OC: osteoclast; OM: osteomacs; BM: bone marrow. Slides were imaged using a Zeiss Axioplan fluorescence microscope.

\subsection{OsteoMacs}

Discoveries surrounding macrophage functionality within the bone marrow have attributed different roles to them based on their spatial localization. Macrophages resident at the bone marrow stroma are often interrelated with erythroid precursors to support erythropoiesis [41]. Macrophages situated at the periosteal and endosteal surfaces, called OsteoMacs, provide bone-forming signals during bone apposition [42,43] (Fig. 2C). In line with the above, macrophages express a variety of osteoinductive factors, including transforming growth factor- $\beta$ (TGF- $\beta$ ), bone morphogenetic protein (BMP)-2 and 1,25-dihydroxyvitamin $\mathrm{D}_{3}$ [44-46]; conversely, osteoblasts sustain macrophage growth and proliferation through colony-stimulating factor-1 (CSF-1) production [47].
Depletion of macrophages in vivo indicates a complete loss of endosteal OsteoMacs, loss of neighboring osteoblasts, decrease in osteoblast-produced cytokines including Ang-1, stem cell factor (SCF; also known as kit-ligand) and chemokine CXC-ligand 12 (CXCL12) and induces HSC mobilization [48]. The conclusions regarding the critical role of this immune component in bone physiology and hematopoietic stem cells metabolism reveal a codependence scenario between OsteoMacs and osteoblasts.

\subsection{Chemokine CXC-ligand 12 and CXCL12-abundant reticular cells}

Recently, Ding and Morrison [49] suggested that HSCs reside adjacent to the perivascular niche whereas early lymphoid 
progenitors inhabit the endosteal niche. Data concerning the significance of the perivascular region within the bone marrow indicate that HSCs localize near reticular cells that express high levels of CXCL12 [9,18,50]. CXCL12 is expressed by perivascular stromal cells, as well as by endothelial cells and osteoblasts [50,51]. The binding of CXCL12 to its physiological receptor CXCR4 provides signals for HSC maintenance and homing, as well as for B cell, plasmacytoid dendritic cell and natural killer (NK) cell maturation [50,52-54]. The CXCL12-abundant reticular (CAR) cells, which are mesenchymal progenitors, have the capacity to differentiate into osteoblasts and adipocytes, to participate in the osteogenic process at the endosteum level and to organize the hematopoietic microenvironment $[8,12,55]$. Based on their anatomical location, CAR cells orchestrate HSCs, lymphoid and erythroid progenitor cell metabolism via cytokines production, such as the SCF and the CXCL12, which are essential for hematopoietic niche maintenance and retention in the bone marrow. CAR cell ablation reduces the number of HSCs by about $50 \%$ in the marrow and increase splenic HSCs. For this reason, CAR cells have been characterized as one of the major niche-signal providers involved in HSC and hematopoietic progenitor homeostasis [55]. An interesting approach from Omatsu et al. [55] suggests that CAR cells exert a regulatory activity on HSCs. CAR population can maintain HSCs in an undifferentiated state or can inhibit the myeloid differentiation of HSCs. Furthermore, the same authors argue that CAR cells could produce adipogenic and osteogenic markers such as PPAR $\gamma$, RUNX2 and Osterix enhancing MSC differentiation. It is also mentioned that CAR cells and/or osteoblasts regulate monocyte migration from the bone marrow into the circulation during an inflammatory stimulus [56]. This observation is consistent with results following the conditional deletion of Cxcl12 in osteoprogenitors that lead to HSC migration toward the blood and spleen [55] and influence the chemotaxis of these hematopoietic elements.

\subsection{Calcium-sensing receptor}

Chemotaxis of selective bone marrow populations is controlled by ionic calcium through the calcium-sensing receptor (CaSR), which is a G-protein-coupled receptor expressed in osteoblasts but also in hematopoietic cells. Variations in calcium ion concentration play specific roles in bone modelling and remodelling, whereas calcium reaches levels of $40 \mathrm{mM}$ near active osteoclasts [57]. In vitro findings have shown that local calcium concentration regulates cell morphology through cellcell or cell-matrix interactions, leading to an augmented Ang-1 and connexin43 expression in osteoblasts [58]. Adams et al. [59] show that HSCs preferentially localize near cells releasing extracellular calcium and the CaSRs upholding the HSCs in close juxtaposition to the endosteal surface and, consequently, to the regulatory niche-maintaining factors. The influence of CaSR on HSC homeostasis is also evident in CaSR knockout mice, which are characterized by hypercalcaemia, bone marrow hypocellularity, absence of paratrabecular hematopoietic clusters and engraftment defects [59]. Indeed, on the one hand, CaSR-/ - mice exhibit reduced ability to bind the extracellular matrix molecules expressed from endosteal cells, such as collagen I [59], and, on the other hand, calcium/CaSR signalling promotes CXCR4/CXCL12 expression and, thus, HSC homing and retention [60]. These data identify a molecular network that exceeds the regulatory microenvironment of the single niche and unifies the endosteal and perivascular elements within a unique homeostatic scenario. The calcium ion presence at the endosteum coupled with the ability of CaSRs, CAR cells and osteomacs to signal for HSCs adhesion and homing strongly support this view.

\subsection{Stem cell factor and matrix metalloproteinases}

Research in the field has provided additional elements to support the hypothesis that the perivascular stromal cells and endothelial cells are two key functional components for the maintenance of HSCs through SCF production. The SCF, expressed by bone marrow fibroblast, osteoblasts, Cxcl12-expressing perivascular stromal cells, endothelial cells and Nestin-expressing mesenchymal stem cells [18,55,61], has been proposed as an important mediator for the preservation of HSC dynamics [62]. In accordance, Heissing et al. [63] have suggested that matrix metalloproteinase-9 (MMP-9) exerts a fundamental role on SCF release, and, consequently, SCF production facilitates bone marrow recovery under myelosuppression or stress conditions through accelerating hematopoietic reconstruction. Early studies on matrix metalloproteinases revealed the implication of MMP-9 in cytokine production, which triggers angiogenesis and osteoclast recruitment [64-66]. Bone marrow hematopoietic cells and MSCs express MMP-9 and, noteworthy, in MMP-9-/- mice a severe drop in hematopoietic clusters at the endosteal and vascular areas has been observed. In addition, exogenous SCF administration in MMP-9-/- animals restores bone marrow hypocellularity, accelerates stem cell differentiation and hematopoietic reconstitution after bone marrow ablation [63]. These considerations underscore the physiological significance of MMP-9-induced release of SCF to support hematopoiesis in a steady-state scenario or after myelosuppression. The evidence that cytokines, such as CXCL12, vascular endothelial growth factor (VEGF) and granulocytes colony stimulating factor (G-CSF), enhance MMP-9 production [63], provides additional criteria for defining the niche functions.

\subsection{Nestin-expressing MSCS}

Nestin is an intermediate filament protein expressed in various progenitor cells and endothelial cells [67]. Nestinexpressing MSCs are a special bone marrow cell population that can differentiate into mesenchymal lineages contributing to skeletal remodelling. These cells present a perivascular distribution adjacent to the bone and neighboring with HSCs and adrenergic nerve fibers. Indeed Nestin ${ }^{+}$cells show a close physical association with HSCs and express genes that regulate the hematopoietic progenitor niche such as Cxcl12, c-kit ligand, angiopoietin-1, interleukin 7, vascular cell adhesion molecule- 1 and osteopontin. Likewise, it has been established that HSCs rapidly home near Nestin ${ }^{+}$cells and the depletion of these cells results in a reduction of HSCs within the bone marrow [18].

In conjunction with Nestin ${ }^{+}$cell properties, some studies have shown the critical role of the sympathetic nervous system in bone marrow stem cell homeostasis. Nestin ${ }^{+}$MSCs express the $\beta 3$-adrenergic receptor and play an indirect role in sympathetic nerve regulation of HSC mobility [18]. In fact, $\beta$-adrenergic receptors signal through the sinusoidal osteoprogenitor cells and influence HSC egression from the bone marrow via Cxcl12 suppression [68]. Another approach by Yamazaki et al. [69] has upheld that nonmyelinating Schwann cells (glial cells) laying in proximity to blood vessels in the marrow not only express stem cell niche genes but also regulate the TGF$\beta /$ Smad signal, which is characterized as one of the critical niche signals involved in HSC homeostasis. The discoveries surrounding Nestin ${ }^{+}$MSCs and glial cell-functions dictate a coordinated and balanced regulation of marrow inhabitants, which act in a controlled spatial manner to finally preserve HSC maintenance and MSC homeostasis. 


\section{Niche vs. niche: an "unbearable" hypothesis or a peculiar niche regulation?}

It is well documented that MSCs, as well as HSCs, inhabit the endosteal and central regions of the bone marrow, with singular proliferative and immunomodulatory activities [70]. MSCs, localized at the sinusoids, have been portrayed as perisinusoidal stromal cells and attributed with specific functional roles within the bone marrow [8,71]. Explicit structural sections provide regulatory signals to maintain the stem cell pool and the niche size. Several studies have revealed that the various niches dwell in two distinct anatomical compartments: the sinusoidal and the endosteal compartments [21,72,73]. Analogously, skeletal and hematopoietic progenitors, which allocate at the same microenvironment within the long bones, are in competition for the marrow space, and further, the osteolineage cells orchestrate a variety of stimuli and interactions that control the niche dimensions $[61,14,74,21]$. For instance, bone calcium ions, which accumulate at the endosteum, influence the HSC niche expansion via calcium sensing receptors expressed by the hematopoietic progenitor cells [59]. In addition, the fact that osteopontin, a sialoprotein produced by osteoblasts, interacts with HSCs, enhances their migration toward the endosteal district and limits the number of stem cells [75-77], strongly supports the above niche-dimension hypothesis. The spatial and temporal relationships between the niches clearly illustrate the composite regulatory network of bone marrow. Thus, the bone residents (including HSCs, MSCs and the mature bone and hematopoietic cells) exchange molecular mediators, which sustain their homing, self-renewal, proliferation, differentiation and shape the niche confines. This niche dualism and competition can also shift toward a basal or a pathological bone metabolism through the control of the inflammatory signals and the bone remodelling process.

\section{Bone remodelling under bone marrow components ascendancy}

Physiological bone remodelling is the result of the coordinated efforts of bone-forming cells, the osteoblasts, and the boneresorbing cells, the osteoclasts [4]. As mentioned, OsteoMacs have specific functions in bone deposition and mineralization and thus are defined as the third player in bone remodelling [78]. Since the remodelling process occurs at the trabecular and cortical surfaces of the bone, a substantial overlap of molecules and regulatory mechanisms, shared between bone and immune cells, emerges. The receptor activator of nuclear factor-kappa B (RANK) ligand (RANKL), a Tumor Necrosis Factor (TNF) superfamily member that is expressed by osteoblasts, plays a key role in osteoclastogenesis. The RANKL binding to its RANK receptor at the surface of osteoclast precursors prompts receptor trimerization and the activation of signalling cascades which drives osteoclast formation and migration at distinct areas called basic multicellular units (BMU). Within the BMU area, the osteoclasts begin resorption of the old or damaged bone [79]. Following the resorptive phase, the osteoblasts recruited to the BMU secrete collagenous and noncollagenous proteins for extracellular matrix deposition and bone formation [80] (Fig. 2D).

The osteoclast activity is not only crucial for bone homeostasis but also extends to the maintenance and mobilization of immature hematopoietic progenitors. Notably, stem cell anchorage molecules, such as SCF and osteopontin, have lower expression after RANKL stimulation. Instead, in PTP $\varepsilon$-knockout mice, characterized by defective osteoclast (and macrophage) functions, RANKL had impaired effects on HSC progenitor mobilization [81]. Mature osteoclasts also produce interleukin (IL)-8 and the proteolytic enzyme MMP-9, both factors involved in progenitor bone marrow cell mobilization [63,82]. In addition, pre-osteoclasts express CXCR4 that respond to CXCL12 and in turn increase MMP-9 production [83]. Taking into account that osteoclast precursors are attracted by CXCL12 signals [83], CXCR4 ablation results in compromised osteoclast recruitment within the BMU area and reduced bone-resorption and MMP-9 expression. Kollet et al. [81] propose an archetypal paradigm of the multiple actions of osteoclasts. Once osteoclasts reach the BMU area, MMP-9 (which are able to degrade all components of the ECM as the other MMPs family proteins) and cathepsin $\mathrm{K}$ (a type I collagen protease) exert a bone-resorbing action, and, furthermore, incite CXCL12 degradation and bone marrow progenitor cell mobilization. Thus, osteoclasts perform a dual function: degrading the endosteal niche components and enhancing egression of HSC progenitors to the circulation due to the disruption of their anchorage potential [81]. It is noteworthy how osteoclasts, both in undifferentiated and mature stages, coordinate bone marrow component kinetics, even though earlier studies identified the granulocyte colony-stimulating factor (G-CSF) as the principal stem cell mobilization factor [84]. On the contrary, it has been proposed that osteoclast-less or impaired osteoclast functioning does not necessarily prohibit HSC progenitor mobilization, and the osteoclast-induced HSC-egression role remains controversial and case specific [85]. Interesting speculation by Purton and Scadden [86] suggests that osteoclastinduced cell mobility results in a bone stroma-surveillance mechanism which guards against the overpopulation of the bone marrow area or/and fine tunes the apparatus that coordinate hematopoiesis. The clinical significance of the above findings is in line with the development of the transplantation methodologies based on mobilizing agent treatments.

The physical competitor of RANKL action is a member of the TNF receptor superfamily, called osteoprotegerin (OPG), which operates as a decoy receptor for RANKL. As an osteo-anabolic/antiRANKL factor, OPG prevents osteoclast activation and controls bone loss [87-89]. In this context, transgenic and knockout animals have been employed to interpret the role of the RANKL/ OPG axis. With reference to the Opg gene functions, it has been reported that Opg deficiency results in bone disorders characterized by decreased bone density and increased osteoclast activity due to an overwhelming RANKL function [4], while OPG overexpression results in severe osteopetrosis in mice [90] caused by the failure of osteoclast formation via complete RANKL inhibition. Polymorphisms in the Opg gene in humans are associated with an increased incidence of fractures due to a lower mineral density $[4,91]$. It is also noteworthy that disruption or functional mutations in Rankl or Rank result in autosomal recessive osteopetrosis both in mice [92-96] and humans [97,98]. In addition, 15-base pair tandem duplications in the RANK gene were observed in patients diagnosed with expansile skeletal hyperphosphatasia [99]. On the other hand, when RANKL overwhelms the effects of OPG, as occurs in RANKL transgenic mice [100] and in postmenopausal osteoporosis [101], the imbalance in bone remodelling results in bone resorption. As a consequence, the primary mechanism of osteoclast regulation and bone remodelling has been ascribed to the RANKL/OPG ratio.

Likewise, the Wnt signalling pathway plays an essential role in bone formation, and the osteo-anabolic effects of the canonical Wnt cascade culminates with $\beta$-catenin stabilization, nuclear translocation and gene transcription activation including c-myc and OPG [102]. It is well known that canonical Wnt signalling decreases CXCL12 bone marrow concentrations and facilitates osteoblasts commitment and differentiation with concurrent RANKL/OPG ratio regulation [103]. Thus, the coordinated action of CXCL12, RANKL and OPG, in part arranged by the Wnt secreted proteins, designate the bone remodelling process and the mobilization of the participants within the BMU areas. Still, the 
augmented OPG expression observed in CXCR4- $-1-$ mice reveals the relevance of CXCR4 in osteoclastogenesis and osteoclast recruitment for the initiation of bone resorption. Based on these findings, CXCL12/CXCR4 signalling in osteoblasts has been recently portrayed as playing a preeminent role regarding MSCs and osteoclast precursor pool size and the recruitment of osteoclasts and osteoblasts in the bone remodelling sites [104]. Indeed, either suppression of the osteoblast lineage or osteoblast-specific CXCR4 deletion accounts for deregulated bone marrow CXCL12 expression and thus impaired bone-remodelling modulation [104,105].

Antithetically, CXCL12 overexpression in the synovial space and the bone tissue of patients with rheumatoid arthritis (RA) aggravates bone disruptive episodes through osteoclasts recruited to the inflamed locus [106]. In point of fact, the key role of CXCL12 in bone and cartilage destruction in pathological scenarios such as osteoporosis, arthritis and metastatic bone cancers is under broad investigation (reviewed in 107).

The CXCL12 accomplishment in bone marrow physiology and bone remodelling progression has recently been correlated with a bioactive sphingolipid metabolite, the sphingosine-1-phosphate (S1P). S1P is also synthesized by osteoblast and osteoclasts and both cell types express its receptors, $\mathrm{S}_{1} \mathrm{P}_{1}$ and $\mathrm{S}_{1} \mathrm{P}_{2}$ [108]. The balance between CXCL12 in the bone marrow and the S1P in the circulation has been portrayed as one of the principal coordinators of stem cell mobilization. Although S1P concentrations are higher in the blood, bone marrow concentrations generate an operational plateau that implicates osteoblast and osteoclast motility, survival, differentiation and adhesion [reviewed in 109]. Simultaneously, the S1P/CXCL12 molecular interchanges tune the bone remodelling through chemotactic instructions and signalling cascade activation such as Rac $\mathrm{S}_{1} \mathrm{P}_{1}$-induced and the Rho $\mathrm{S}_{1} \mathrm{P}_{2}$-induced mechanisms [110]. On the other hand, S1P overabundance in synovial fluids, as previously described for the CXCL12, meets the pathological RA scenery and drives pro-inflammatory cytokines/ chemokines production [111].

\section{Mature hematopoietic cells coordinate bone marrow homeostasis}

Accumulating evidence suggests that both mediators of the adaptive immune system, $\mathrm{B}$ and $\mathrm{T}$ cells, can carry out osteoinductive or osteodestructive features and preserve bone homeostasis. In point of fact, these mature hematopoietic cells produce $20 \%$ RANKL in basal conditions, whereas in an inflammatory context (RA or periodontal tissue diseases) the percentage rises to $50 \%$ for $\mathrm{B}$ cells and $90 \%$ for T cells [112,113]. In accordance thereto, Manabe et al. [114] report that B cells are a major source of endogenous RANKL in bone marrow, and B-lymphoid lineage cells, and in earlier developmental stages, may have the potential to differentiate into osteoclasts once treated with the osteoclastogenic M-CSF and soluble RANKL in vitro. M-CSF binds to its receptor c-Fms on the surface of osteoclast precursors and signals similarly to RANKL/ RANK promoting osteoclast survival, activation and differentiation [115]. Furthermore, it is well established that T cells play a central role in the mechanism of ovariectomy (ovx)-induced bone loss. The estrogen deficiency induces T-cell tumor necrosis factor (TNF) expression and, in turn, the induction of osteoclastogenesis [116]. These findings were further sustained by the fact that ovx fails to induce catabolic effects in bone in T cell deficient nude mice [116118]. It is also remarkable that the dendritic cells may influence RANKL production in $T$ cells and augment bone loss within an inflammatory scenario $[119,120]$. Within a synergistic plateau, $\mathrm{T}$ cells may regulate the $\mathrm{B}$ cell-production of various molecules involved in bone turnover. B cells can enhance or overwhelm osteoclastogenesis when stimulated by Th2 or Th1 cytokines, respectively [121]. The anti-inflammatory cytokines produced by
Th cells such as interferon (IFN)- $\alpha$, IFN- $\beta$, IFN- $\gamma$, IL-4, IL-5, IL-10, IL-12, IL-13 and IL-18, as well as TGF- $\beta$ and PTH, have been classified as RANKL signalling inhibitors $[122,123]$. Conversely, IL-1, IL-3, IL-6, IL-7, IL-11, IL-17, as well as prostaglandin (PG) E2 and TNF, have been characterized as pro-inflammatory moderators leading to pathological osteoclastogenesis via RANKL expression $[12,124]$. Moreover, several cytokines (i.e. TNF and IL-1) can act with RANKL within a combined scenario to directly aggravate bone resorption [125]. Another T-helper cell subset with an osteoclastogenic feature is Th17 which produces IL-17, and is involved in matrix metalloproteinases synthesis and bone matrix degradation [126]. Recent findings emphasize the fact that the anti-inflammatory Foxp $3^{+}$regulatory T cells (Treg) could converse into Th17 cells in autoimmune arthritis. The Foxp3 expression furnishes the suppressive ability of the Treg cells. Komatsu et al. [127], considering the inflammatory microenvironment of arthritis, have observed that $\mathrm{CD} 25^{\mathrm{lo}} \mathrm{Foxp} 3^{+} \mathrm{CD} 4^{+} \mathrm{T}$ cells downregulate Foxp3 expression and undergo transdifferentiation into Th17 cells. Th17 express high levels of RANKL resulting in osteoclastogenic induction and enhanced inflammation. Treg plasticity is a considerable illustration of bone marrow component ductility under pathologic conditions such as in RA. Opposing views have posited that RANK/RANKL interaction plays a crucial role in peripheral $\mathrm{CD}^{+} \mathrm{CD}_{25}{ }^{+} \mathrm{FoxP}^{+}$Treg homeostasis, while RANKLstimulated Treg expansion could convoy anti-inflammatory responses [128]. Although several findings identify $\mathrm{T}$ cells as one of the principal bone marrow regulators in basal or in pathological conditions, emerging research has highlighted the combined effort of the $\mathrm{T}$ and $\mathrm{B}$ cells within bone cavities. In addition to T-cells, OPG expression has also been detected in Blymphocytes, which participate in B cell hematopoiesis and the maintenance of bone mass. Of interest, mature B cell OPGsecretion accounts for about $40 \%$ of the total OPG production composing a regulatory homeostatic network between B cells, MSCs and osteoblasts [reviewed in 129]. Li et al. [130] assert that under basal conditions B-cell RANKL secretion remains at low levels. The same authors state that activated T cells and CD40/ CD40L interaction serve as regulatory stimuli in osteoclastogenesis stimulating B cell-OPG production within a physiological tableau. Indeed, CD40/CD40L knockout mice have been attributed an osteoporotic phenotype with a significant decrease in bone marrow OPG levels [131]. Not to mention that in pathological conditions B-cell derived OPG plays a watchdog role in osteoclast maturation and prevents bone destruction [130]. This provides a comprehensive picture of how the coadjuvancy of these two immune populations coordinates bone marrow components. The complexity of bone marrow homeostatic steadiness can be evaluated if we consider the fact that the marrow inhabitants of the hematopoietic lineage could exert pro- or anti-inflammatory actions based on the clinical milieu. Although activated T cells have the capacity to secrete osteoclastogenic cytokines, such as RANKL and TNF [132,133], it has also been asserted that they conjointly exert anti-osteoclastogenic effects through cytokines secretion such as IL-4 [133].

Neutrophil granulocytes are also implicated in RANKL production and osteoclastogenic activity in inflammatory circumstances [134]. Another protagonist in the bone marrow microenvironment is megacaryocyte, which has the potential to drive bone formation or resorption through RANKL or OPG production [135]. The discrepancies concerning the anabolic or catabolic effects of the immune cells on bone could be due to the different clinical conditions and the compromised niche-to-niche communication within the bone marrow. The impaired cross-talk between the bone marrow stromal and hematopoietic components results in pathologic conditions like chronic inflammatory diseases, such as RA [136,137] and chronic arthritis [138], whereas chronic immune 
activation disrupts the dynamic equilibrium of bone homeostasis [125].

\section{Growth factors and hormone accomplishment within bone marrow}

Bone marrow research has brought to the fore the functional relationship between the niches and the regulatory molecular network of cytokines, growth hormones and receptors. Modern developments in understanding the accomplishment of immune components in bone homeostasis have established that $\mathrm{T}$ cells play a critical role in regulating the bone-remodelling outcomes of PTH, an important calcium-phosphate modulator. Namely, T cells respond to intermittent PTH treatment and enhance osteoblast differentiation through a Wnt10b/Wnt osteoblastogenic related mechanism [139-141]. The PTH osteogenic activity and its consequential capacity to expand the bone niche space have also been correlated with the increase of the HSC pool and HSC maintenance. In point of fact, PTH-induced specific mediators on bone-lining cell and on HSC, such as N-cadherin, Wnt/B-catenin and Notch/Jagged1, promote LT-HSC engraftment toward the niche [61,142]. Mendez-Ferrer et al. [18] have associated HSC expansion after PTH administration with an increment in $\mathrm{Nestin}^{+}$MSCs, highlighting the quintessential role of the various bone marrow components, including the adventitial reticular cells and the sympathetic neuronal fibers, in HSCs and MSCs homeostasis. Parallel studies using genetically modified mice as regards the PTH receptor (PPR) established that PPR represents a crucial modulator of the bone marrow ontogeny and, therefore, of the fate of HSCs and MSCs [74]. Conversely, continuous PTH administration switches the metabolic scenario toward a catabolic stance. For instance, $\mathrm{T}$ cells mediate PTH-induced bone loss in hyperparathyroidism through the CD40L/CD40 signalling network [143]. Our previous research brought to light the relevance of PTH on osteoblast metabolism and the close liaison of fibroblast growth factor-2 (FGF-2) in this process [144]. The effects of FGF-2 on the skeletal and hematopoietic stem cells have been a subject of controversy. From one point of view, FGF-2 is acknowledged as an anabolic bone agent that enhances bone formation by stimulating MSC proliferation and differentiation in a stage-dependent manner $[145,146]$. More than that, FGF signalling regulates the hematopoietic developmental events during either early or late differentiation phase [147,148]. Recent findings by Zhao et al. [149] reveal that FGF receptor-1 (FGFR1)-mediated response supports HSC proliferation and facilitates HSC egression to the circulation, both unavoidable conditions for post-injury hematopoietic recovery. These observations have revealed the concurrence of the FGF pathway as part of the hematopoietic stress response and have given prominence to FGFR1 attendance, acting as a moderator of NF-kB, CXCL12/CXCR4, AKT and MAPK signalling within the bone marrow. According to a divergent standpoint, FGF-2 abrogates the hematopoietic activity and induces compensatory extramedullary hematopoiesis. These adverse FGF-2 effects occur at a molecular level, due to the disruption on the CXCL12/CXCR4 axis to Ang-1decreased and osteopontin-increased expression, contingencies that result in a restricted stem cell pool and compromised MSCsupported HSC homing $[8,150,151]$. Keeping in mind that a highlevel of seric FGF-2 incites anemia, osteomalacia [152], and clonal myeloid disorders correlated with severe hematopoietic defects [153], it is reasonable to deduce that the benefits of this growth factor on HSC and MSC homeostasis depend on intramedullary FGF-2 production levels and serum concentrations. To circumvent the deleterious effects of high doses of FGF-2, Meng et al. [151] have developed an erythroid-specific promoter of FGF-2, which controls FGF-2 concentrations in serum and in the marrow cavity, and, consequently, leads to trabecular bone formation. In our previous studies, using gain-of-function and loss-of-function approaches, we set out the FGF-2 interrelationship on bone morphogenetic protein (BMP)-2 osteogenic activity and we underscored the importance of the crosstalk between both factors in the osteoblast metabolism [154-156]. BMP signalling plays multiple roles in bone, bone marrow vascularization and MSC homeostasis [157]. Therefore, BMP receptor type IA (BMPRIA) mutations generate dissimilar phenomena in function of the area/ niche. Of note, in Bmpr1a mutant mice, there is an abnormal bone formation and trabecular bone-like area alteration, as well as increased numbers of SNO cells and LT-HSCs [14]. Recently, a mouse model with BMP-2 abrogation in early osteoblasts displayed compromised micro-capillary architecture, decreased $\alpha$-smooth muscle actin ( $\alpha$-SMA) ${ }^{+}$MSCs (Fig. 2E, F), CD31 and CD146 cell pool, coupled with decreased Ang-1 production, and reduced levels in vascular endothelial growth factor A (VegfA) within the bone marrow [157]. Considering that the VegfA has been characterized as a significant moderator in blood vessel formation and in osteoblast precursor maturation [158], and that the $\alpha-\mathrm{SMA}^{+}$cell lineage has been involved in angiogenesis during bone formation [159], it is fathomable that the BMP-2 signal transduction mechanism can provide extra criteria for the abovementioned manipulation of the bone marrow microenvironment.

Several studies have explained the spatio-temporal osteogenic action of BMP-2 and its clear-cut role in MSC differentiation into osteoblast progenitors. The destiny of preosteoblasts, among other bone marrow stimuli, is controlled by TGF- $\beta 1$, a potent regulatory cytokine produced by multiple cell types [reviewed in 160]. Indeed, TGF- $\beta 1$ exerts controlling effects on the bone remodelling process and has both stage-dependent osteoclastogenic activities (as a result of NF-kB and RANK induction), and osteoprotective functions regarding the imbalance of the OPG/RANKL axis via OPG upregulation [161]. TGF- $\beta$ produced by glial cells also behaves as a perivascular niche modulator supporting HSC maintenance [69]. The TGF- $\beta$ response is in accordance with its concentrations levels within the bone marrow. Low TGF- $\beta$ levels support Th17 maturation and consequently osteoclastogenesis, while elevated levels of this factor sustain Treg-induced MSCs-mediated osteoblastogenesis [162]. The TGF- $\beta$ activity presents a molecular circuit wherein more influential factors such as FGF-2, PTH and the prostaglandins (PGs) have been engaged into a synergistic module, to become part of the canvas of marrow signalling interactions. As regards the involvement of PGs within the bone marrow, our research, along with that of others, has shown the involvement of these lipid mediators in bone cells as well as in skeletal and hematopoietic progenitors. Particularly, PGE2 and PGF2 $\alpha$ exert a bifold dose/stage-depended action on osteoblast and osteoclast metabolism in cell and organ cultures [163,164]. The PGF2 $\alpha$ mitogenic and survival effects on osteoblasts were mediated by FGF-2 [165], underlining the importance of FGF signalling in the skeletal and, as previously mentioned, on hematopoietic cells. Concurrently, other findings have focused attention on the ability of PGE2 to facilitate either HSC engraftment via CXCR4 upregulation or HSC egression into the circulation and to provide antiapoptotic signals on HSCs via surviving production [166]. PGE2 can also amplify the PTH effects in the marrow cavity with dissimilar outcomes, based on the clinical profile of the bone and the hematopoietic components [167]. Thus, based on the abovedescribed factors, it is explicable that the molecular mechanisms within the Daedalean bone marrow entity assume distinct bias in basal or pathological (inflammatory) conditions.

\section{Complexities and perplexities of bone marrow topography}

The findings that the stromal elements have a direct impact on HSCs homeostasis have established over the last two decades a 
unique paradigm for the potency of the bone marrow niche. The various specialized cell clusters are delineated in distinct structural areas with conspicuous commitments, such as the bone marrow adaptability to support HSC homing, egression and cycling, as well as MSC differentiation and engagement to the endosteal and perivascular area.

The importance of every single component in the bone marrow ontogeny is conditioned by complexities and perplexities caused by the considerable interactions amongst the distinct anatomical compartments within the axial and long bone cavity. These complexities arise out of the fine-tuned hematopoietic mechanisms that sustain HSCs and blood cell maturation, as well as the bone marrow microenvironment, which tends to preserve the HSC pool at the stable number of $1.1 \times 10^{4}$ cells in all mammalian systems [168]. Bone formation and humoral immune system maturation is based on strong ties between the niche components. For instance, osteoblasts by RANKL and OPG secretion coordinate B cell development but only in the precise spatial limits of the "hematopoietic workroom." Outside these "B cell maturation borders," RANKL and OPG carry out different functions (i.e. osteoblastogenic/osteoclastogenic activities) [reviewed in 169]. But how do these molecules respect the topographic limitations and act in a niche/context specific way without being dissipated into other functional compartments with, in some cases, deleterious consequences? Up to this point, a clear-cut answer has not been found.

In a thought-provoking study, Bianco [21] has addressed a captivating question regarding the contribution of the osteoblasts to HSC homing and maintenance. A perplexity arises out of the fact that osteoblasts, from the point of view of osteogenic functionality, have a rigorous spatio-temporal existence and thus a transient life at the endosteum level. Consequently, since the HSCs allocated at the endosteal niche have to deal with endosteal behavior, the whole "niche" dimension tends to depend on the limited life span of the osteoblasts. Alternatively, the osteoblast influences on HSCs homeostasis remain contingent to an extended regulatory scenario, which involves additional homeostatic players in the bone marrow, such as the MSCs, initially identified as stem cells and thus far considered multirole elements, such as contributors to the HSC niche physiology [reviewed in 5]. In addition, the extramedullary engraftment of the HSCs in the absence or impaired expression of key regulatory factors within the marrow area, such as the calcium-sensing receptor, resulted in perplexities regarding the specified "niche harbour" properties of the bone marrow. Indeed, Sacchetti et al. [8] have shown how bone marrow MSCs (perisinusoidal CD146 ${ }^{+}$cells) can establish an effective hematopoietic habitat outside the boundaries of the bone marrow. In line with this, Serafini et al. [170] have shown in a wider scope that the heterotopic "ossicles" generated by transplantation of bone marrow-derived MSCs and by non-mineralized cartilage pellets formed by bone marrow stromal cells have reproduced a functionally extramedullary HSC niche. Due to the architectural and operational posture of these heterotopic "ossicles," it has become clear that a role of the MSC is to generate hematopoietic vascularized microenvironments and emulate the skeletal hematopoietic niche assembly.

Recently, it has been described another complex scenario, which bring into question the topographic niche limitations: the suppression of key factors involved in the endocondral ossification process, including osterix and VEGF, results in compromised niche formation and HSC retention [171]. Hence, the endocondral ossification mechanisms, which act within a predesignated local microenvironment, become an additional issue for the consideration of the niche ontogeny.

The above concerns, which are quite crucial for understanding the bone marrow ontogeny, are particularly important for determining the MSC magnitude and the HSC demands, in terms of microenvironmental constructural/homeostatic characteristics. Although modern findings have unveiled salient clues for defining the mosaic of the bone marrow ontongeny, there is still a long way to go. Undoubtedly, the in vitro approaches do not always meet the real scale of the bone marrow concern due to the lack of many significant niche regulators, and the in vivo research has to deal with systemic organism vicissitudes, and, therefore, the improvement of schemes/assays is warranted. Resolving the complexities and perplexities associated with bones and bone marrow remains a compelling task for further research to address.

\section{Conclusion}

The bone marrow reservoir accommodates an extraordinarily multipart microenvironment that tends to merge the singular features of the diverse cell populations in a labyrinthine homeostatic tableau. The progenitor/stem and mature components that inhabit the bone marrow cavity deal with a broad range of intramural and external molecules and preserve the characteristic plasticity, consistency and functionality of the bone marrow compartments. This dynamic hematopoietic and mesenchymal stem cell incubator, enclosed within the axial and long bones, in physiological conditions, could be identified as the body's ground control, involved, for example, in bone modelling and remodelling, immune cell egression and maturation and cooling down proinflammatory stimuli. The bone marrow regulatory activities go beyond its topography and meet the needs of other tissues and organs (i.e. muscles, adipose tissue and kidney) in terms of the release of cytokines/chemokines, the control of phosphate/calci$\mathrm{um}$, the production of growth factors, their distribution through circulation, etc. It is also a tremendous cell breeding locus, where the disruption of the functionality of even one of its residents can lead to local or systemic pathological conditions, such as chronic inflammation, kidney failure, bone diseases and hematopoietic disorders.

\section{Disclosure statement}

The authors have nothing to disclose.

\section{Acknowledgements}

The authors are grateful for the financial support of Camerino University (FAR 2013)

\section{References}

[1] Morrison SJ, Weissman IL. The long-term repopulating subset of hematopoietic stem cells is deterministic and isolatable by phenotype. Immunity 1994:8:661-73.

[2] Cheshier SH, Morrison SJ, Liao X, Weissman IL. In vivo proliferation and cell cycle kinetics of long-term self-renewing hematopoietic stem cells. Proc Natl Acad Sci USA 1999;96:3120-5.

[3] Bradford GB, Williams B, Rossi R, Bertoncello I. Quiescence, cycling, and turnover in the primitive hematopoietic stem cell compartment. Exp Hematol 1997;25:445-53.

[4] Nakashima T, Hayashi M, Takayanagi H. New insights into osteoclastogenic signaling mechanisms. Trends Endocrinol Metab 2012;23:582-90.

[5] Bianco P, Cao X, Frenette PS, Mao JJ, Robey PG, Simmons PJ, et al. The meaning, the sense and the significance: translating the science of mesenchymal stem cells into medicine. Nat Med 2013;19:35-42.

[6] Simmons CA, Matlis S, Thornton AJ, Chen S, Wang CY, Mooney DJ. Cyclic strain enhances matrix mineralization by adult human mesenchymal stem cells via the extracellular signal-regulated kinase (ERK1/2) signaling pathway. J Biomech 2003;36:1087-96.

[7] Schofield R. The relationship between the spleen colony-forming cell and the haemopoietic stem cell. Blood Cells 1978;4:7-25.

[8] Sacchetti B, Funari A, Michienzi S, Di Cesare S, Piersanti S, Saggio I, et al. 2007 Self-renewing osteoprogenitors in bone marrow sinusoids can organize a hematopoietic microenvironment. Cell 2007;131:324-36. 
[9] Kiel MJ, Yilmaz OH, Iwashita T, Terhorst C, Morrison SJ. SLAM family receptors distinguish hematopoietic stem and progenitor cells and reveal endothelial niches for stem cells. Cell 2005;121:1109-21.

[10] Spradling A, Drummond-Barbosa D, Kai T. Stem cells find their niche. Nature 2001;414:98-104.

[11] Agas D, Marchetti L, Capitani M, Sabbieti MG. The dual face of parathyroid hormone and prostaglandins in the osteoimmune system. Am J Physiol Endocrinol Metab 2013;305:E1185-94.

[12] Danks L, Takayanagi H. Immunology and bone. J Biochem 2013;154:29-39.

[13] Taichman RS, Reilly MJ, Emerson SG. The hematopoietic microenvironment: osteoblasts and the hematopoietic microenvironment. Hematology 2000;4:421-6.

[14] Zhang J, Niu C, Ye L, Huang H, He X, Tong WG, et al. Identification of the haematopoietic stem cell niche and control of the niche size. Nature 2003;425:836-41.

[15] El-Badri NS, Wang BY, Cherry, Good RA. Osteoblasts promote engraftment of allogeneic hematopoietic stem cells. Exp Hematol 1998;26:110-6.

[16] Ohishi M, Schipani E. PTH and stem cells. J Endocrinol Invest 2011;34:552-6.

[17] Kiel MJ, Radice GL, Morrison SJ. Lack of evidence that hematopoietic stem cells depend on N-cadherin-mediated adhesion to osteoblasts for their maintenance. Cell Stem Cell 2007;16:204-17.

[18] Méndez-Ferrer S, Michurina TV, Ferraro F, Mazloom AR, Macarthur BD, Lira SA, et al. Mesenchymal and haematopoietic stem cells form a unique bone marrow niche. Nature 2010;466:829-34.

[19] Gong JK. Endosteal marrow: a rich source of hematopoietic stem cells. Science 1978;199:1443-5.

[20] Kiel MJ, Morrison SJ. Maintaining hematopoietic stem cells in the vascular niche. Immunity 2006;25:862-4.

[21] Bianco P. Minireview: The Stem Cell Next Door: Skeletal and Hematopoietic Stem Cell "Niches" in Bone. Endocrinology 2011;152:2957-62.

[22] Kiel MJ, Yilmaz OH, Iwashita T, Yilmaz OH, Terhorst C, Morrison SJ. SLAM family receptors distinguish hematopoietic stem and progenitor cells and reveal endothelial niches for stem cells. Cell 2005;121:1109-21.

[23] Kiel MJ, Acar M, Radice GL, Morrison SJ. Hematopoietic stem cells do not depend on N-cadherin to regulate their maintenance. Cell Stem Cell 2009;6:170-9.

[24] Arai F, Hirao A, Ohmura M, Sato H, Matsuoka S, Takubo K, et al. Tie2/angiopoietin-1 signaling regulates hematopoietic stem cell quiescence in the bone marrow niche. Cell 2004;118:149-61.

[25] Arai F, Yoshihara H, Hosokawa K, Nakamura Y, Gomei Y, Iwasaki H, et al. Niche regulation of hematopoietic stem cells in the endosteum. Ann N Y Acad Sci 2009;1176:36-46.

[26] Avecilla ST, Hattori K, Heissig B, Tejada R, Liao F, Shido K, et al. Chemokinemediated interaction of hematopoietic progenitors with the bone marrow vascular niche is required for thrombopoiesis. Nat Med 2004;10:64-71.

[27] Li P, Zon LI. Resolving the controversy about N-cadherin and hematopoietic stem cells. Cell Stem Cell 2010;6:199-202.

[28] Arai F, Suda T. Quiescent stem cells in the niche. StemBook, ed. The Stem Cell Research Community, StemBook; 2008 July 11 . http://dx.doi.org/10.3824/ stembook.1.6.1.

[29] Suda T, Arai F, Hirao A. Hematopoietic stem cells and their niche. Trends Immunol. 2005;26:426-33.

[30] Kaushansky K. Thrombopoietin: the primary regulator of megakaryocyte and platelet production. Thromb Haemost 1995;74(July (1)):521-5.

[31] Alexander WS, Roberts AW, Nicola NA, Li R, Metcalf D. Deficiencies in progenitor cells of multiple hematopoietic lineages and defective megakaryocytopoiesis in mice lacking the thrombopoietic receptor c-Mpl. Blood 1996;87:2162-70.

[32] Kimura S, Roberts AW, Metcalf D, Alexander WS. Hematopoietic stem cell deficiencies in mice lacking c-Mpl, the receptor for thrombopoietin. Proc Natl Acad Sci USA 1998;95:1195-200.

[33] Qian H, Buza-Vidas N, Hyland CD, Jensen CT, Antonchuk J, Månsson R, et al. Critical role of thrombopoietin in maintaining adult quiescent hematopoietic stem cells. Cell Stem Cell 2007;1:671-84.

[34] Buza-Vidas N1, Antonchuk J, Qian H, Månsson R, Luc S, Zandi S, et al. Cytokines regulate postnatal hematopoietic stem cell expansion: opposing roles of thrombopoietin and LNK. Genes Dev 2006;1:2018-23.

[35] Wilson A, Murphy MJ, Oskarsson T, Kaloulis K, Bettess MD, Oser GM, et al. cMyc controls the balance between hematopoietic stem cell self-renewal and differentiation. Genes Dev 2004;18:2747-63.

[36] Potocnik AJ, Brakebusch C, Fässler R. Fetal and adult hematopoietic stem cells require beta1 integrin function for colonizing fetal liver, spleen, and bone marrow. Immunity 2000;12:653-63.

[37] Hattori K, Dias S, Heissig B, Hackett NR, Lyden D, Tateno M, et al. Vascular endothelial growth factor and angiopoietin-1 stimulate postnatal hematopoiesis by recruitment of vasculogenic and hematopoietic stem cells. J Exp Med 2001;193:1005-14.

[38] Dumont DJ, Yamaguchi TP, Conlon RA, Rossant J, Breitman ML. tek, a novel tyrosine kinase gene located on mouse chromosome 4, is expressed in endothelial cells and their presumptive precursors. Oncogene 1992;7:1471-80.

[39] Sato A, Iwama A, Takakura N, Nishio H, Yancopoulos GD, Suda T. Characterization of TEK receptor tyrosine kinase and its ligands, Angiopoietins, in human hematopoietic progenitor cells. Int Immunol 1998;10:1217-27.

[40] Arai F, Ohneda O, Miyamoto T, Zhang XQ, Suda T. Mesenchymal stem cells in perichondrium express activated leukocyte cell adhesion molecule and participate in bone marrow formation. J Exp Med 2002;195:1549-63.
[41] Mohandas N, Prenant M. Three-dimensional model of bone marrow. Blood 1978;51:633-43

[42] Pettit AR, Chang MK, Hume DA, Raggatt LJ. Osteal macrophages: a new twist on coupling during bone dynamics. Bone 2008;43:976-82.

[43] Alexander KA, Chang MK, Maylin ER, Kohler T, Müller R, Wu AC, et al. Osteal macrophages promote in vivo intramembranous bone healing in a mouse tibial injury model. J Bone Miner Res 2011;26:1517-32.

[44] Wahl SM, McCartney-Francis N, Allen JB, Dougherty EB, Dougherty SF. Macrophage production of TGF-beta and regulation by TGF-beta. Ann N Y Acad Sci 1990;593:188-96.

[45] Kreutz M, Andreesen R, Krause SW, Szabo A, Ritz E, Reichel H. 1,25-Dihydroxyvitamin D3 production and vitamin D3 receptor expression are developmentally regulated during differentiation of human monocytes into macrophages. Blood 1993;82:1300-7.

[46] Honda Y, Anada T, Kamakura S, Nakamura M, Sugawara S, Suzuki O. Elevated extracellular calcium stimulates secretion of bone morphogenetic protein 2 by a macrophage cell line. Biochem Biophys Res Commun 2006;345: $1155-60$.

[47] Cecchini MG, Hofstetter W, Halasy J, Wetterwald A, Felix R. Role of CSF-1 in bone and bone marrow development. Mol Reprod Dev 1997;46:75-83.

[48] Winkler IG, Sims NA, Pettit AR, Barbier V, Nowlan B, Helwani F, et al. Bone marrow macrophages maintain hematopoietic stem cell (HSC) niches and their depletion mobilizes HSCs. Blood 2010;116:4815-28.

[49] Ding L, Morrison SJ. Haematopoietic stem cells and early lymphoid progenitors occupy distinct bone marrow niches. Nature 2013;495:231-5.

[50] Sugiyama T, Kohara H, Noda M, Nagasawa T. Maintenance of the hematopoietic stem cell pool by CXCL12-CXCR4 chemokine signaling in bone marrow stromal cell niches. Immunity 2006;25:977-88.

[51] Dar A, Goichberg P, Shinder V, Kalinkovich A, Kollet O, Netzer N, et al. Chemokine receptor CXCR4-dependent internalization and resecretion of functional chemokine SDF-1 by bone marrow endothelial and stromal cells. Nat Immunol 2005;6:1038-46.

[52] Nagasawa T. Microenvironmental niches in the bone marrow required for Bcell development. Nat Rev Immunol 2006;6:107-16.

[53] Kohara H, Omatsu Y, Sugiyama T, Noda M, Fujii N, Nagasawa T. Development of plasmacytoid dendritic cells in bone marrow stromal cell niches requires CXCL12-CXCR4 chemokine signaling. Blood 2007;110: 4153-60.

[54] Noda M, Omatsu Y, Sugiyama T, Oishi S, Fujii N, Nagasawa T. CXCL12-CXCR4 chemokine signaling is essential for NK-cell development in adult mice. Blood 2011;117:451-8.

[55] Omatsu Y, Sugiyama T, Kohara H, Kondoh G, Fujii N, Kohno K, et al. The essential functions of adipo-osteogenic progenitors as the hematopoietic stem and progenitor cell niche. Immunity 2010;33:387-99.

[56] Sugiyama T, Nagasawa T. Bone marrow niches for hematopoietic stem cells and immune cells. Inflamm Allergy Drug Targets 2012;11:201-6.

[57] Silver IA, Murrills RJ, Etherington DJ. Microelectrode studies on the acid microenvironment beneath adherent macrophages and osteoclasts. Exp Cell Res 1988;175:266-76.

[58] Nakamura S, Matsumoto T, Sasaki J, Egusa H, Lee KY, Nakano T, et al. Effect of calcium ion concentrations on osteogenic differentiation and hematopoietic stem cell niche-related protein expression in osteoblasts. Tissue Eng Part A 2010;16:2467-73.

[59] Adams GB, Chabner KT, Alley IR, Olson DP, Szczepiorkowski ZM, Poznansky MC, et al. Stem cell engraftment at the endosteal niche is specified by the calcium-sensing receptor. Nature 2006;439:599-603.

[60] Wu Q, Shao H, Darwin ED, Li J, Li J, Yang B, et al. Extracellular calcium increases CXCR4 expression on bone marrow-derived cells and enhances proangiogenesis therapy. J Cell Mol Med 2009;13:3764-73.

[61] Calvi LM, Adams GB, Weibrecht KW, Weber JM, Olson DP, Knight MC, et al. Osteoblastic cells regulate the haematopoietic stem cell niche. Nature 2003;425:841-6.

[62] Ding L, Saunders TL, Enikolopov G, Morrison SJ. Endothelial and perivascular cells maintain haematopoietic stem cells. Nature 2012;481 457-62.

[63] Heissig B, Hattori K, Dias S, Friedrich M, Ferris B, Hackett NR, et al. Recruitment of stem and progenitor cells from the bone marrow niche requires MMP-9 mediated release of kit-ligand. Cell 2002;109:625-37.

[64] Vu TH, Werb Z. Matrix metalloproteinases: effectors of development and normal physiology. Genes Dev 2000;14:2123-33.

[65] Bergers G, Brekken R, McMahon G, Vu TH, Itoh T, Tamaki K, et al. Matrix metalloproteinase-9 triggers the angiogenic switch during carcinogenesis. Nat Cell Biol 2000;2:737-44.

[66] Engsig MT, Chen QJ, Vu TH, Pedersen AC, Therkidsen B, Lund LR, et al. Matrix metalloproteinase 9 and vascular endothelial growth factor are essential for osteoclast recruitment into developing long bones. J Cell Biol 2000;151: 879-90.

[67] Day K, Shefer G, Richardson JB, Enikolopov G, Yablonka-Reuveni Z. NestinGFP reporter expression defines the quiescent state of skeletal muscle satellite cells. Dev Biol 2007;304:246-59.

[68] Katayama Y1, Battista M, Kao WM, Hidalgo A, Peired AJ, Thomas SA, et al. Signals from the sympathetic nervous system regulate hematopoietic stem cell egress from bone marrow. Cell 2006;124:407-21.

[69] Yamazaki S, Ema H, Karlsson G, Yamaguchi T, Miyoshi H, Shioda S, et al Nonmyelinating Schwann cells maintain hematopoietic stem cell hibernation in the bone marrow niche. Cell 2011;147:1146-58. 
[70] Siclari VA, Zhu J, Akiyama K, Liu F, Zhang X, Chandra A, et al. Mesenchymal progenitors residing close to the bone surface are functionally distinct from those in the central bone marrow. Bone 2013;53:575-86.

[71] Bianco P, Robey PG, Simmons PJ. Mesenchymal stem cells: revisiting history, concepts, and assays. Cell Stem Cell 2008;2:313-9.

[72] Kiel MJ, Morrison SJ. Uncertainty in the niches that maintain haematopoietic stem cells. Nat Rev Immunol 2008;8:290-301.

[73] Garrett RW, Emerson SG. Bone and blood vessels: the hard and the soft of hematopoietic stem cell niches. Cell Stem Cell 2009:4:503-6.

[74] Kuznetsov SA, Riminucci M, Ziran N, Tsutsui TW, Corsi A, Calvi L, et al. The interplay of osteogenesis and hematopoiesis: expression of a constitutively active $\mathrm{PTH} / \mathrm{PTHrP}$ receptor in osteogenic cells perturbs the establishment of hematopoiesis in bone and of skeletal stem cells in the bone marrow. J Cel Biol 2004; $167: 1113-22$

[75] Nilsson SK, Johnston HM, Whitty GA, Williams B, Webb RJ, Denhardt DT, et al. Osteopontin, a key component of the hematopoietic stem cell niche and regulator of primitive hematopoietic progenitor cells. Blood 2005;106: 1232-9.

[76] Stier S, Ko Y, Forkert R, Lutz C, Neuhaus T, Grünewald E, et al. Osteopontin is a hematopoietic stem cell niche component that negatively regulates stem cell pool size. J Exp Med 2005;201:1781-91.

[77] Ballen K. Targeting the stem cell niche: squeezing blood from bones. Bone Marrow Transplant 2007:39:655-60.

[78] Chang MK, Raggatt LJ, Alexander KA, Kuliwaba JS, Fazzalari NL, Schroder K, et al. Osteal tissue macrophages are intercalated throughout human and mouse bone lining tissues and regulate osteoblast function in vitro and in vivo. J Immunol 2008;181:1232-44.

[79] Takayanagi H. Osteoimmunology: shared mechanisms and crosstalk between the immune and bone systems. Nat Rev Immunol 2007;7:292-304

[80] Takayanagi H. Osteoimmunology and the effects of the immune system on bone. Nat Rev Rheumatol 2009;5:667-76.

[81] Kollet O, Dar A, Shivtiel S, Kalinkovich A, Lapid K, Sztainberg Y, et al. Osteoclasts degrade endosteal components and promote mobilization of hematopoietic progenitor cells. Nat Med 2006;12:657-64.

[82] Rothe L, Collin-Osdoby P, Chen Y, Sunyer T, Chaudhary L, Tsay A, et al. Human osteoclasts and osteoclast-like cells synthesize and release high basal and inflammatory stimulated levels of the potent chemokine interleukin-8. Endocrinology 1998;139:4353-63.

[83] Wright LM, Maloney W, Yu X, Kindle L, Collin-Osdoby P, Osdoby P. Stroma cell-derived factor-1 binding to its chemokine receptor CXCR4 on precursor cells promotes the chemotactic recruitment, development and survival of human osteoclasts. Bone 2005;36:840-53.

[84] Takamatsu Y, Simmons PJ, Moore RJ, Morris HA, To LB, Lévesque JP. Osteoclast-mediated bone resorption is stimulated during short-term administration of granulocyte colony-stimulating factor but is not responsible for hematopoietic progenitor cell mobilization. Blood 1998;92: 3465-73.

[85] Miyamoto K, Yoshida S, Kawasumi M, Hashimoto K, Kimura T, Sato Y, et al. Osteoclasts are dispensable for hematopoietic stem cell maintenance and mobilization. J Exp Med 2011;208:2175-81.

[86] Purton LE, Scadden DT. Osteoclasts eat stem cells out of house and home. Nat Med 2006;12:610-1.

[87] Lacey DL, Timms E, Tan HL, Kelley MJ, Dunstan CR, Burgess T, et al. Osteoprotegerin ligand is a cytokine that regulates osteoclast differentiation and activation. Cell 1998:93:165-76.

[88] Saidenberg-Kermanac'h N, Cohen-Solal M, Bessis N, De Vernejoul MC, Boissier MC. Role for osteoprotegerin in rheumatoid inflammation. Joint Bone Spine 2004:71:9-13.

[89] Raggatt LJ, Partridge NC. Cellular and molecular mechanisms of bone remodeling. J Biol Chem 2010;285:25103-08

[90] Simonet WS, Lacey DL, Dunstan CR, Kelley M, Chang MS, Lüthy R, et al. Osteoprotegerin: a novel secreted protein involved in the regulation of bone density. Cell 1997;89:309-19.

[91] Yamada Y, Ando F, Niino N, Shimokata H. Association of polymorphisms of the osteoprotegerin gene with bone mineral density in Japanese women but not men. Mol Genet Metab 2003;344-9.

[92] Kong YY, Yoshida H, Sarosi I, Tan HL, Timms E, Capparelli C, et al. OPGL is a key regulator of osteoclastogenesis, lymphocyte development and lymph-node organogenesis. Nature 1999;397:315-23.

[93] Kim N, Odgren PR, Kim DK, Marks Jr SC, Choi Y. Diverse roles of the tumor necrosis factor family member TRANCE in skeletal physiology revealed by TRANCE deficiency and partial rescue by a lymphocyte-expressed TRANCE transgene. Proc Natl Acad Sci USA 2000;97:10905-10.

[94] Douni E, Rinotas V, Makrinou E, Zwerina J, Penninger JM, Eliopoulos E, et al. A RANKL G278R mutation causing osteopetrosis identifies a functional amino acid essential for trimer assembly in RANKL and TNF. Hum Mol Genet 2012;21:784-98.

[95] Dougall WC1, Glaccum M, Charrier K, Rohrbach K, Brasel K, De Smedt T, et al. RANK is essential for osteoclast and lymph node development. Genes Dev 1999;13:2412-24.

[96] Li J1, Sarosi I, Yan XQ Morony S, Capparelli C, Tan HL, et al. RANK is the intrinsic hematopoietic cell surface receptor that controls osteoclastogenesis and regulation of bone mass and calcium metabolism. Proc Natl Acad Sci USA 2000;97:1566-71.

[97] Sobacchi C, Frattini A, Guerrini MM, Abinun M, Pangrazio A, Susani L, et al. Osteoclast-poor human osteopetrosis due to mutations in the gene encoding RANKL. Nat Genet 2007;39:960-2.
[98] Guerrini MM, Sobacchi C, Cassani B, Abinun M, Kilic SS, Pangrazio A, et al. Human osteoclast-poor osteopetrosis with hypogammaglobulinemia due to TNFRSF11A (RANK) mutations. Am J Hum Genet 2008;83:64-76.

[99] Whyte MP, Hughes AE. Expansile skeletal hyperphosphatasia is caused by a 15-base pair tandem duplication in TNFRSF11A encoding RANK and is allelic to familial expansile osteolysis. J Bone Miner Res 2002;17:26-9.

[100] Rinotas V1, Niti A, Dacquin R, Bonnet N, Stolina M, Han CY, et al. Novel genetic models of osteoporosis by overexpression of human RANKL in transgenic mice. J Bone Miner Res 2014;29:1158-69.

[101] Eghbali-Fatourechi G1, Khosla S, Sanyal A, Boyle WJ, Lacey DL, Riggs BL. Role of RANK ligand in mediating increased bone resorption in early postmenopausal women. J Clin Invest 2003;111:1221-30.

[102] MacDonald B, Tamai K, He X. Wnt/beta-catenin signaling: components, mechanisms, and diseases. Dev Cell 2009;17:9-26.

[103] Tamura M, Sato MM, Nashimoto M. Regulation of CXCL12 expression by canonical Wnt signaling in bone marrow stromal cells. Int J Biochem Cell Biol 2011;43:760-7.

[104] Shahnazari M, Chu V, Wronski TJ, Nissenson RA, Halloran BP. CXCL12/CXCR4 signaling in the osteoblast regulates the mesenchymal stem cell and osteoclast lineage populations. FASEB J 2013;27:3505-13.

[105] Christopher MJ, Liu F, Hilton MJ, Long F, Link DC. Suppression of CXCL12 production by bone marrow osteoblasts is a common and critical pathway for cytokine-induced mobilization. Blood 2009;114:1331-9.

[106] Grassi F, Cristino S, Toneguzzi S, Piacentini A, Facchini A, Lisignoli G. CXCL12 chemokine up-regulates bone resorption and MMP-9 release by human osteoclasts: CXCL12 levels are increased in synovial and bone tissue of rheumatoid arthritis patients. J Cell Physiol 2004;199:244-51.

[107] Gronthos S, Zannettino AC. In: Zon LI, editor. Hematopoiesis: A developmental Approach 718-726. New York: Oxford Univ. Press; 2001.

[108] Ishii M, Kikuta J. Sphingosine-1-phosphate signaling controlling osteoclasts and bone homeostasis. Biochim Biophys Acta 2013;1831:223-7.

[109] Golan K, Kollet O, Lapidot T. Dynamic cross talk between S1P and CXCL12 regulates hematopoietic stem cells migration. Develop Bone Remodel. Pharmaceut (Basel) 2013;6:1145-69.

[110] Ishii M, Kikuta J, Shimazu Y, Meier-Schellersheim M, Germain RN. Chemorepulsion by blood $\mathrm{s} 1 \mathrm{p}$ regulates osteoclast precursor mobilization and bone remodeling in vivo. J Exp Med 2010;207:2793-8.

[111] Hu PF, Chen Y, Cai PF, Jiang LF, Wu LD. Sphingosine-1-phosphate: a potential therapeutic target for rheumatoid arthritis. Mol Biol Rep 2011;38:4225-30.

[112] Takayanagi H, Ogasawara K, Hida S, Chiba T, Murata S, Sato K, et al. T-cellmediated regulation of osteoclastogenesis by signalling cross-talk between RANKL and IFN-gamma. Nature 2000;408:600-5.

[113] Kawai T, Matsuyama T, Hosokawa Y, Makihira S, Seki M, Karimbux NY, et al. B and $\mathrm{T}$ lymphocytes are the primary sources of RANKL in the bone resorptive lesion of periodontal disease. Am J Pathol 2006;169:987-98.

[114] Manabe N, Kawaguchi H, Chikuda H, Miyaura C, Inada M, Nagai R, et al. Connection between B lymphocyte and osteoclast differentiation pathways. J Immunol 2001;167:2625-31

[115] Khosla S. Minireview: the OPG/RANKL/RANK system. Endocrinology 2001.

[116] Cenci S, Weitzmann MN, Roggia C, Namba N, Novack D, Woodring J, et al Estrogen deficiency induces bone loss by enhancing T-cell production of TNFalpha. J Clin Invest 2000;106:1229-37.

[117] Roggia C, Gao Y, Cenci S, Weitzmann MN, Toraldo G, Isaia G, et al. Upregulation of TNF-producing T cells in the bone marrow: a key mechanism by which estrogen deficiency induces bone loss in vivo. Proc Natl Acad Sci USA 2001;98:13960-65.

[118] Pacifici R. Role of T cells in ovariectomy induced bone loss-revisited. J Bone Min Res 2012;27:231-9.

[119] Santiago-Schwarz F, Anand P, Liu S, Carsons SE. Dendritic cells (DCs) in rheumatoid arthritis (RA): progenitor cells and soluble factors contained in RA synovial fluid yield a subset of myeloid DCs that preferentially activate Th1 inflammatory-type responses. J Immunol 2001;167: 1758-68.

[120] Page G, Miossec P. RANK and RANKL expression as markers of dendritic cell-T cell interactions in paired samples of rheumatoid synovium and lymph nodes. Arthritis Rheum 2005;52:2307-12.

[121] Choi Y, Kim JJ. B cells activated in the presence of Th1 cytokines inhibit osteoclastogenesis. Exp Mol Med 2003;35:385-92.

[122] Datta HK, Ng WF, Walker JA, Tuck SP, Varanasi SS. The cell biology of bone metabolism. J Clin Pathol 2008;61:577-87.

[123] Caetano-Lopes J, Canhão H, Fonseca JE. Osteoimmunology - the hidden immune regulation of bone. Autoimmun Rev 2009;8:250-855.

[124] Kong YY, Feige U, Sarosi I, Bolon B, Tafuri A, Morony S, et al. Activated T cells regulate bone loss and joint destruction in adjuvant arthritis through osteoprotegerin ligand. Nature 1999;402:304-9.

[125] Hardy R, Cooper MS. Bone loss in inflammatory disorders. J Endocrinol 2009;201:309-20.

[126] David JP. Osteoimmunology: a view from the bone. Adv Immunol 2007;95:149-65.

[127] Komatsu N, Okamoto K, Sawa S, Nakashima T, Oh-hora M, Kodama T, et al. Pathogenic conversion of Foxp3+ T cells into TH17 cells in autoimmune arthritis. Nat Med 2014;20:62-8.

[128] Loser A, Mehling S, Loeser J, Apelt A, Kuhn S, Grabbe. et al. Epidermal RANKL controls regulatory T-cell numbers via activation of dendritic cells. Nat Med 2006; $12: 1372-9$. 
[129] Manilay JO, Zouali M. Tight relationships between B lymphocytes and the skeletal system. Trends Mol Med. 2014;20:405-12.

[130] Li Y, Toraldo G, Li A, Yang X, Zhang H, Qian WP, et al. B cells and T cells are critical for the preservation of bone homeostasis and attainment of peak bone mass in vivo. Blood 2007:109:3839-48.

[131] O’Brien C, Fu Q, Mommsen L, Dusevich V, Bone Weitzmann ald L, Manolagas SC, et al. Osteoblasts are not the source of RANKL and OPG in bone but are required for maintenance of OC function. J Bone Min Res 2006;22(Supplement 1). abstract.

[132] Weitzmann MN, Cenci S, Rifas L, Haug J, Dipersio J, Pacifici R. T cell activation induces human osteoclast formation via receptor activator of nuclear factor kappaB ligand-dependent and -independent mechanisms. J Bone Miner Res 2001;16:328-37.

[133] Pacifici R. The immune system and bone. Arch Biochem Biophys 2010;503:41-53

[134] Poubelle PE, Chakravarti A, Fernandes MJ, Doiron K, Marceau AA. Differential expression of RANK, RANK-L, and osteoprotegerin by synovial fluid neutrophils from patients with rheumatoid arthritis and by healthy human blood neutrophils. Arthritis Res Ther 2007;9:R25.

[135] Lorenzo J, Horowitz M, Choi Y. Osteoimmunology: interactions of the bone and immune system. Endocr Rev 2008;29:403-40.

[136] Fonseca JE, Cortez-Dias N, Francisco A, Sobral M, Canhão H, Resende C, et al. Inflammatory cell infiltrate and RANKL/OPG expression in rheumatoid synovium: comparison with other inflammatory arthropathies and correlation with outcome. Clin Exp Rheumatol 2005;23:185-92.

[137] Herman S, Kronke G, Schett G. Molecular mechanisms of inflammatory bone damage: emerging targets for therapy. Trends Mol Med 2008;14: 245-53.

[138] Caetano-Lopes J, Nery AM, Henriques R, Canhão H, Duarte J, Amaral PM, et al. Chronic arthritis directly induces quantitative and qualitative bone disturbances leading to compromised biomechanical properties. Clin Exp Rheumatol 2009;27:475-82.

[139] Geffner ME, Bersch N, Cortez AB, Bailey RC, Golde DW. Growth-promoting actions of parathyroid hormone, adrenocorticotrophic hormone, and thyroid-stimulating hormone: in vitro studies in normal and pygmy T-lymphoblast cell lines. Pediatr Res 1995;37:507-11.

[140] Rifas L, Arackal S, Weitzmann MN. Inflammatory T cells rapidly induce differentiation of human bone marrow stromal cells into mature osteoblasts. J Cell Biochem 2003;88:650-9.

[141] Terauchi M, Li JY, Bedi B, Baek KH, Tawfeek H, Galley S, et al. T lymphocytes amplify the anabolic activity of parathyroid hormone through Wnt10b signalling. Cell Metab 2009;10:229-40.

[142] Pacifici R. Role of T cells in the modulation of PTH action: physiological and clinical significance. Endocrine 2013;44:576-82.

[143] Gao Y, Wu X, Terauchi M, Li JY, Grassi F, Galley S, et al. T cells potentiate PTHinduced cortical bone loss through CD40L signaling. Cell Metab 2008;8: $132-45$.

[144] Sabbieti MG, Agas D, Xiao L, Marchetti L, Coffin JD, Doetschman T, et al. Endogenous FGF-2 is critically important in PTH anabolic effects on bone. J Cell Physiol 2009;219:143-51.

[145] Nakamura K, Kawaguchi H, Aoyama I, Hanada K, Hiyama Y, Awa T, et al. Stimulation of bone formation by intraosseous application of recombinant basic fibroblast growth factor in normal and ovariectomized rabbits. J Orthop Res 1997; 15:307-13.

[146] Fakhry A, Ratisoontorn C, Vedhachalam C, Salhab I, Koyama E, Leboy P, et al. Effects of FGF-2/-9 in calvarial bone cell cultures: differentiation stagedependent mitogenic effect, inverse regulation of BMP-2 and noggin, and enhancement of osteogenic potential. Bone 2005:36:254-66.

[147] Faloon P, Arentson E, Kazarov A, Deng CX, Porcher C, Orkin S, et al. Basic fibroblast growth factor positively regulates hematopoietic development. Development 2000;127:1931-41.

[148] Akashi K, He X, Chen J, Iwasaki H, Niu C, Steenhard B, et al. Transcriptional accessibility for genes of multiple tissues and hematopoietic lineages is hierarchically controlled during early hematopoiesis. Blood 2003;101: 383-9.

[149] Zhao M, Ross JT, Itkin T, Perry JM, Venkatraman A, Haug JS, et al. FGF signaling facilitates postinjury recovery of mouse hematopoietic system. Blood 2012;120:1831-42.

[150] Nakayama T, Mutsuga N, Tosato G. FGF2 posttranscriptionally down-regulates expression of SDF1 in bone marrow stromal cells through FGFR1 IIIc. Blood 2007;109:1363-72.

[151] Meng X, Baylink DJ, Sheng M, Wang H, Gridley DS, Lau KH, et al. Erythroid promoter confines FGF2 expression to the marrow after hematopoietic stem cell gene therapy and leads to enhanced endosteal bone formation. PLoS One 2012; 7:e37569.

[152] Hall SL, Lau KH, Chen ST, Wergedal JE, Srivastava A, Klamut H, et al. Sca-1(+) hematopoietic cell-based gene therapy with a modified FGF-2 increased endosteal/trabecular bone formation in mice. Mol Ther 2007;15:1881-9.

[153] Tefferi A. Myelofibrosis with myeloid metaplasia. N Engl J Med 2000;342: 1255-65.

[154] Naganawa T, Xiao L, Coffin JD, Doetschman T, Sabbieti MG, Agas D, et al. Reduced expression and function of bone morphogenetic protein-2 in bones of Fgf2 null mice. J Cell Biochem 2008;103:1975-88.

[155] Sabbieti MG, Agas D, Marchetti L, Coffin JD, Xiao L, Hurley MM. BMP-2 differentially modulates FGF-2 isoform effects in osteoblasts from newborn transgenic mice. Endocrinology 2013;154:2723-33.
[156] Agas D, Marchetti L, Hurley MM, Sabbieti MG. Prostaglandin F2 $\alpha$ : a bone remodeling mediator. J Cell Physiol 2013;228:25-9.

[157] Yang W, Guo D, Harris MA, Cui Y, Gluhak-Heinrich J, Wu J, et al. Bmp2 in osteoblasts of periosteum and trabecular bone links bone formation to vascularization and mesenchymal stem cells. J Cell Sci 2013;126(Pt 18):4085-98.

[158] Liu Y, Berendsen AD, Jia S, Lotinun S, Baron R, Ferrara N, et al. Intracellular VEGF regulates the balance between osteoblast and adipocyte differentiation. J Clin Invest 2012:122:3101-13.

[159] Matsubara H, Hogan DE, Morgan EF, Mortlock DP, Einhorn TA, Gerstenfeld LC. Vascular tissues are a primary source of BMP2 expression during bone formation induced by distraction osteogenesis. Bone 2012;51:168-80.

[160] Kasagi S, Chen W. TGF-beta1 on osteoimmunology and the bone component cells. Cell Biosci 2013;3:4.

[161] Karst M, Gorny G, Galvin RJ, Oursler MJ. Roles of stromal cell RANKL, OPG, and M-CSF expression in biphasic TGF-beta regulation of osteoclast differentiation. J Cell Physiol 2004;200:99-106.

[162] Zhou L, Lopes JE, Chong MM, Ivanov II, Min R, Victora GD, et al. TGF-betainduced Foxp3 inhibits T(H)17 cell differentiation by antagonizing RORgammat function. Nature 2008;453:236-40.

[163] Raisz LG, Fall PM. Biphasic effects of prostaglandin E2 on bone formation in cultured fetal rat calvariae: interaction with cortisol. Endocrinology 1990:126:1654-9.

[164] Sabbieti MG, Agas D, Materazzi S, Capacchietti M, Materazzi G, Hurley MM et al. Prostaglandin F2alpha involves heparan sulphate sugar chains and FGFRs to modulate osteoblast growth and differentiation. J Cell Physiol 2008:217:48-59.

[165] Sabbieti MG, Agas D, Marchetti L, Santoni G, Amantini C, Xiao L, et al Signaling pathways implicated in PGF2alpha effects on Fgf2+/+ and Fgf2osteoblasts. J Cell Physiol 2010;224:465-74.

[166] Hoggatt J, Singh P, Sampath J, Pelus LM. Prostaglandin E2 enhances hematopoietic stem cell homing, survival, and proliferation. Blood 2009;113:544455.

[167] Frisch BJ, Porter RL, Gigliotti BJ, Olm-Shipman AJ, Weber JM, O’Keefe RJ, et al. In vivo prostaglandin E2 treatment alters the bone marrow microenvironment and preferentially expands short-term hematopoietic stem cells. Blood 2009;114:4054-63.

[168] Abkowitz JL, Catlin SN, McCallie MT, Guttorp P. Evidence that the number of hematopoietic stem cells per animal is conserved in mammals. Blood 2002:100:2665-7.

[169] Manilay JO, Zouali M. Tight relationships between B lymphocytes and the skeletal system. Trends Mol Med 2014;20:405-12.

[170] Serafini M, Sacchetti B, Pievani A, Redaelli D, Remoli C, Biondi A, et al. Establishment of bone marrow and hematopoietic niches in vivo by reversion of chondrocyte differentiation of human bone marrow stromal cells. Stem Cell Res 2014;12:659-72.

[171] Chan CK, Chen CC, Luppen CA, Kim JB, DeBoer AT, Wei K, et al. Endochondral ossification is required for haematopoietic stem-cell niche formation. Nature 2009;457:490-4

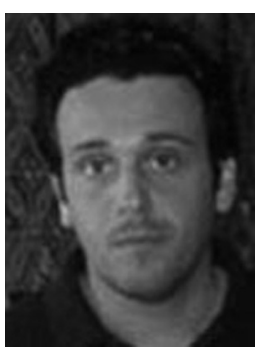

Dimitrios Agas, PhD. Dr. Agas is a researcher in the School of Biosciences and Veterinary Medicine, University of Camerino. During his PhD had studied osteoblasts and mesenchymal stem cells homeostasis as well as the role of growth factors and hormones in osteoblast progenitors maturation and differentiation. These studies were performed in the Department of Medicine of the University of Connecticut Health Center (US) and the School of Biosciences and Veterinary Medicine of the University of Camerino (IT). He also participated in technology transfer competitions, attained grants and awards, and he contributed for the realization of several patents. Nowadays his study is focused on DNA vaccination/immuno modulation and the development of novel approaches against osteoporosis and inflammatory bone diseases. His research interest include whether specific proteins can cool down the inflammatory stimulus and restore the bone and bone marrow homeostasis within a pathological context. These projects are performed with collaboration with the Cure Lab Oncology (US), the Department of Biochemistry of the Boston University School of Medicine (US) and the Laboratory of Genetics, Department of Biotechnology of the Agricultural University of Athens (GR).

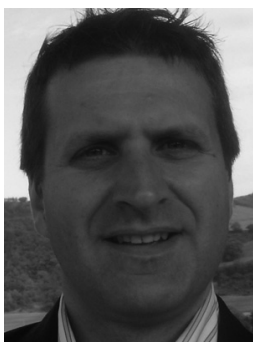

Luigi Marchetti, PhD. Associate professor, School of Biosciences and Biotechnology, University of Camerino-Italy. He received his Bachelor's degree in Biological Sciences (1990) and his PhD in Biology from the University of Camerino (1994). In 1994 he was visiting investigator at the Universite de Rouen, Groupe de Réserche en Endocrinologiemoleculaire under the supervision of Prof. H. Vaudry. In 1996 he was visiting researcher at the University of Connecticut Health Center - Division of Endocrinology and Metabolism - Farmington, CT, USA under the supervision of Prof. A.R. Hand He got a researcher position at the University of Camerino in 1996 at the Department of Molecular, Cellular and Animal Biology. In 2003 he was appointed Associate Professor at the Department of Morphological and Biochemical Sciences, University of Camerino. His last research 
is focused on the impact of endocrine disrupting chemicals on bone and other biological matrices both in vivo and in vitro and on the roles of PGF2alpha, PTH, FGF2 and its receptors on bone metabolism using different approaches. His work is getting published in international peer-reviewed journals and he is reviewer in several scientific journals.

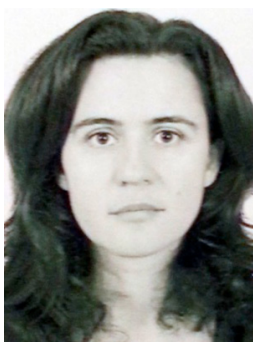

Eleni Douni, PhD. Assistant professor, Department of Biotechnology, Agricultural University of Athens. Associate Researcher, Division of Immunology, BSRC 'Alexander Fleming'. Dr. Douni received her B.Sc. in Biology (1991) and her Ph.D. in Molecular Genetics from the University of Athens (1998) in collaboration with the Hellenic Pasteur Institute (HPI). She continued as postdoc in HPI until 2000 using state-of-the-art technologies for the generation and analysis of transgenic, knockout and conditional knockout mouse models of inflammatory diseases. She joined the Institute of Immunology B.S.R.C. "Al. Fleming”, as a Senior Scientist in 2001 and later as an Assistant Research Professor (2006) establishing her own research group. In 2012 Dr Douni was appointed Assistant Professor at the Laboratory of Genetics of the Department of Biotechnology at the Agricultural University of Athens and maintained her affiliation with Fleming as Associate Researcher. Her research is focused on the identification and characterization of novel disease targets and disease mechanisms by modelling human diseases affecting the immune, bone, or neurological systems, using Functional Genetics approaches in mice. Since 2005 she has actively participated in 10 research grants either as co-investigator or as coordinator. Her work is getting published in wellrespected peer-reviewed journals, she has received over 1500 non-self citations and she is reviewer in a number of scientific journals and funding bodies.

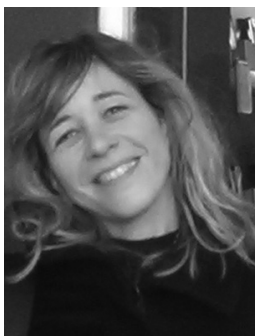

Maria Giovanna Sabbieti, PhD She received her $\mathrm{PhD}$ in Biology (1996) at the University of Camerino (Italy). Then, she continued as a post-PhD fellow in the University of Camerino focusing the research on the study of topics of cell biology with particular regard to the signalling pathways and molecules involved in osteoblasts differentiation and bone formation. This research was conducted in collaboration with the University of Connecticut Health Center Department of Endocrinology and Bone Metabolism where Maria Giovanna spent two years as visiting scientist. From 2009 she is a researcher at the School of Biosciences and Veterinary Medicine, University of Camerino. Actual studies focus on the treatment of inflammatory bone diseases by using a new developed DNA vaccine. This research is performed in collaboration with Prof. Franco Venanzi, University of Camerino, with the CureLab Oncology (USA), the Department of Biochemistry Boston University, and with the Laboratory of Genetics, Department of Biotechnology of the Agricultural University of Athens (GR). The Maria Giovanna studies concretized in more than forty peer-reviewed journals and various patents. 